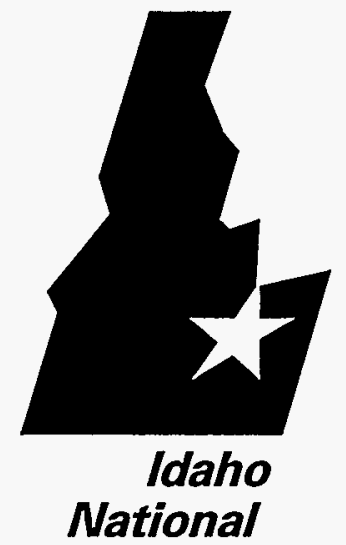

Engineering Laboratory
INEL-96/0021

January 1996

\section{Actinide Partitioning Studies Using Dihexyl-N,N-diethylcarbamoylmethyl Phosphonate And Dissolved Zirconium Calcine}

\author{
RECENED \\ PEB 231960 \\ OSTI
}

K. N. Brewer

R. S. Herbst

J. D. Law

T. G. Garn

R. D. Tillotson

T. A. Todd 


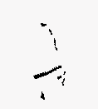




\section{Actinide Partitioning Studies Using Dihexyl-N,N-diethyl- carbamoylmethyl Phosphonate And Dissolved Zirconium Calcine}

K. N. Brewer

R. S. Herbst

J. D. Law

T. G. Garn

R. D. Tillotson

T. A. Todd

January 1996

Idaho National Engineering Laboratory HLW Engineering and Projects Department Lockheed-Martin Idaho Technologies Company Idaho Falls, Idaho 83415



Prepared for the

U. S. Department of Energy

Assistant Secretary for Environmental Management

Under DOE Idaho Operations Office

Contract DE-AC07-94ID13223 


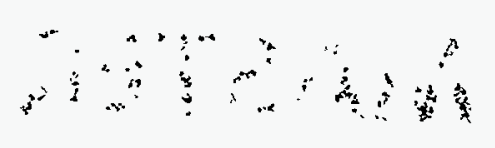

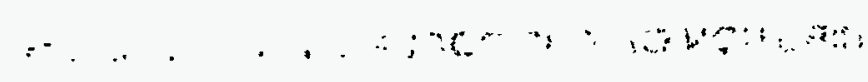




\section{SUMMARY}

A baseline flowsheet capable of partitioning the TRansUranic (TRU) elements from dissolved zirconium calcines has been developed. The goal of the TRU partitioning process is to remove the TRUs from solutions of dissolved zirconium calcines to below the $10 \mathrm{CFR}$ 61.55 Class A waste limit of $10 \mathrm{nCi} / \mathrm{g}$. Extraction, scrub, strip, and wash distribution coefficients for several elements, including the actinides, were measured in the laboratory by performing equal volume batch contacts. A solvent containing dihexyl-N,Ndiethylcarbamoylmethyl phosphonate (CMP), tributylphosphate (TBP), and a branched chain hydrocarbon as the diluent were used to develop this process. A non-radioactive zirconium pilot-plant calcine was spiked with the TRUs, $U, T c$, or a radioactive isotope of zirconium to simulate the behavior of these elements in actual dissolved zirconium calcine feed.

Distribution coefficient data obtained from laboratory testing were used to recommend: 1) solvent composition, 2) scrub solutions capable of selectively removing extracted zirconium while minimizing actinide recycle, 3) optimized strip solutions which quantitatively recover extracted actinides, and 4) feed adjustments necessary for flowsheet efficiency. A solvent composition of $0.5 \mathrm{M}$ CMP, $1.0 \mathrm{M}$ TBP diluted with Isopar $\mathrm{L}^{\circledR}$ is recommended. Scrub solutions containing no more than $0.05 \mathrm{M} \mathrm{H}_{2} \mathrm{C}_{2} \mathrm{O}_{4}$ or $0.1 \mathrm{M} \mathrm{NH}_{4} \mathrm{~F}$, each in $3.0 \mathrm{M} \mathrm{HNO}_{3}$, is recommended for selectively scrubbing zirconium from the solvent. A strip solution between $0.001 \mathrm{M}$ and $0.04 \mathrm{M}$ 1-hydroxyethane-1,1-diphosphonic acid (HEDPA) is recommended for complete actinide recovery.

Laboratory distribution coefficients were used in conjunction with the Generic IRUEX Model (GTM) to develop and recommend a flowsheet for testing in the $5.5-\mathrm{cm}$ Centrifugal Contactor Mockup. GTM results indicate that the recommended flowsheet should remove the actinides from dissolved zirconium calcine feeds to below the Class A waste limit of 10 $\mathrm{nCi} / \mathrm{g}$. Less than $0.01 \mathrm{wt} \%$ of the extracted zirconium will report to the high-activity waste (HAW) fraction using the $0.05 \mathrm{M} \mathrm{H}_{2} \mathrm{C}_{2} \mathrm{O}_{4}$ in $3.0 \mathrm{M} \mathrm{HNO}_{3}$ scrub, and greater than $99 \%$ of the extracted actinides are recovered with $0.001 \underline{\mathrm{M}}$ HEDPA. Modeling results from the GTM indicate this to be a viable flowsheet for testing in the $5.5-\mathrm{cm}$ Centrifugal Contactor Mockup. 







\section{ACKNOWLEDGEMENTS}

Excellent analytical support was provided by the Idaho Chemical Processing Plant's Radiochemical and Spectrochemical Groups. Specifically, Troy Tranter, Chris Ortell, Brian Storms, Lee Hinkley and Mike Evens of the Radiochemical Group and Jeff Laug, Duane Lundholm, and Bryan Zaccardi of the Spectrochemical Group continuously provided quick sample turn around times during this testing. A barrage of tests were performed that inundated these two laboratories with samples. The work performed by these people restored order to the chaos. 


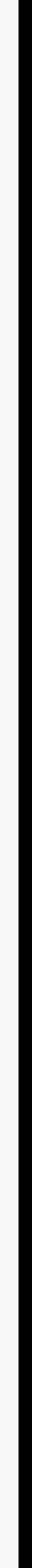




\section{TABLE OF CONTENTS}

SUMMARY $\ldots \ldots \ldots \ldots \ldots \ldots \ldots \ldots \ldots \ldots \ldots \ldots \ldots \ldots \ldots \ldots \ldots \ldots$ iii

ACKNOWLEDGEMENTS $\ldots \ldots \ldots \ldots \ldots \ldots \ldots \ldots \ldots \ldots \ldots \ldots$

TABLE OF CONTENTS $\ldots \ldots \ldots \ldots \ldots \ldots \ldots \ldots \ldots \ldots \ldots \ldots \ldots$ vii

LIST OF FIGURES $\ldots \ldots \ldots \ldots \ldots \ldots \ldots \ldots \ldots \ldots \ldots \ldots \ldots \ldots \ldots \ldots \ldots \ldots \ldots$

LIST OF TABLES $\ldots \ldots \ldots \ldots \ldots \ldots \ldots \ldots \ldots \ldots \ldots \ldots \ldots \ldots \ldots \ldots \ldots \ldots \ldots$ ix

INTRODUCTION $\ldots \ldots \ldots \ldots \ldots \ldots \ldots \ldots \ldots \ldots \ldots \ldots \ldots \ldots \ldots \ldots \ldots \ldots \ldots$



EXPERIMENTAL $\ldots \ldots \ldots \ldots \ldots \ldots \ldots \ldots \ldots \ldots \ldots \ldots \ldots \ldots \ldots \ldots \ldots \ldots \ldots \ldots$

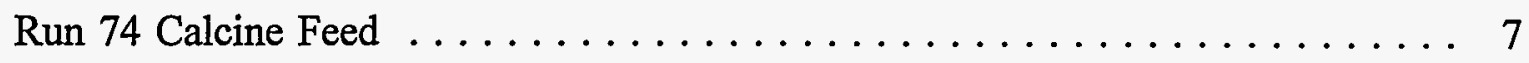

Reagents/Chemicals .................... 7

Experimental Methodology $\ldots \ldots \ldots \ldots \ldots \ldots \ldots \ldots \ldots \ldots \ldots$

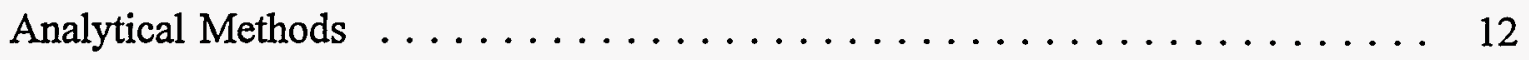

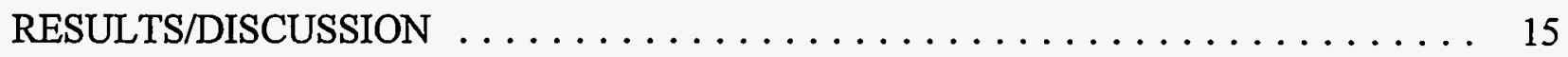





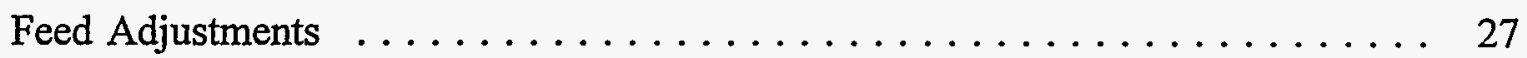

Chromium Extraction $\ldots \ldots \ldots \ldots \ldots \ldots \ldots \ldots \ldots \ldots \ldots \ldots \ldots \ldots \ldots$

Zirconium Extraction $\ldots \ldots \ldots \ldots \ldots \ldots \ldots \ldots \ldots \ldots \ldots \ldots \ldots \ldots \ldots \ldots$

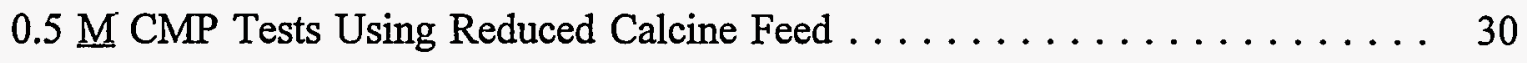

Extraction From Reduced Run 74 Feed $\ldots \ldots \ldots \ldots \ldots \ldots \ldots \ldots$

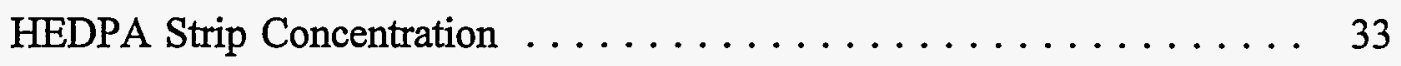

RECOMMENDATIONS $\ldots \ldots \ldots \ldots \ldots \ldots \ldots \ldots \ldots \ldots \ldots \ldots \ldots \ldots \ldots \ldots$

Flowsheet Development Using the Generic TRUEX Model . . . . . . . . . 37

CONCLUSIONS .................................. 39

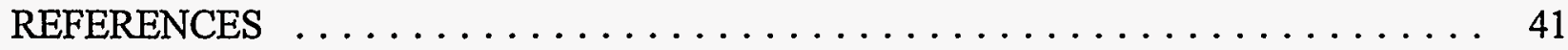




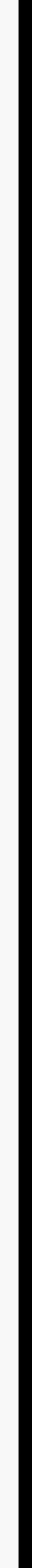




\section{LIST OF FIGURES}

Figure 1: Experimental Procedure used for testing Simulated ICPP Dissolved

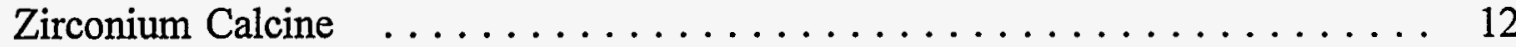

Figure 2: $\mathrm{D}_{\mathrm{Am}}$ as a function of $\left[\mathrm{HNO}_{3}\right]$ using $0.5 \underline{\mathrm{M}} \mathrm{CMP}$ and $1.0 \underline{\mathrm{M}} \mathrm{TBP}$ in

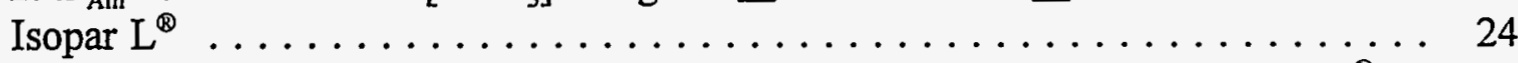

Figure 3: $\mathrm{D}_{\mathrm{Zr}}$ as a function of $\left[\mathrm{HNO}_{3}\right]$ using $0.5 \mathrm{M} \mathrm{CMP}$ and $1.0 \mathrm{M}$ TBP in Isopar $\mathrm{L}^{\otimes} \ldots 24$

Figure 4: CMP Flowsheet for the Treatment of ICPP Dissolved Zirconium Calcine . . . 38

\section{LIST OF TABLES}

Table 1: TRU Activity in Actual Dissolved Zirconium Calcine $\ldots \ldots \ldots \ldots \ldots$

Table 2: Dissolved Run 74 Calcine Feed Composition .................. 8

Table 3: Extraction Distribution Coefficients Using $0.75 \underline{\mathrm{M}} \mathrm{CMP}$ and $1.0 \underline{\mathrm{M}} \mathrm{TBP}$ in

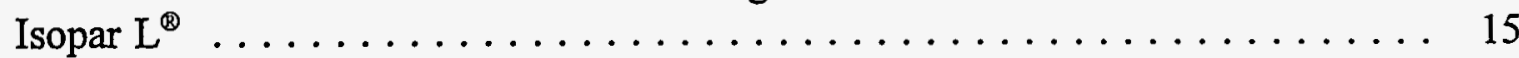

Table 4: Zirconium Scrubbing With $0.05 \mathrm{M} \mathrm{H}_{2} \mathrm{C}_{2} \mathrm{O}_{4}$ in $3 \underline{\mathrm{M}} \mathrm{HNO}_{3}$ or $1.5 \underline{\mathrm{M}} \mathrm{HNO}_{3} \ldots 18$

Table 5: Zirconium and Actinide Scrubbing With $0.1 \mathrm{M} \mathrm{NH}_{4} \mathrm{~F}$ in $3 \mathrm{M} \mathrm{HNO} \mathrm{HN}_{3} \ldots \ldots 18$

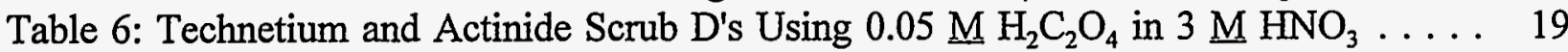

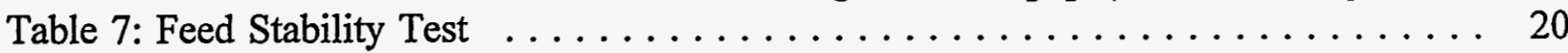

Table 8: Stripping Distribution Coefficients Using $0.04 \underline{\mathrm{M}} \mathrm{HEDPA}$ in $0.04 \underline{\mathrm{M}} \mathrm{HNO}_{3} \quad \ldots \quad 21$

Table 9: Stripping Distribution Coefficients Using $0.05 \mathrm{M} \mathrm{H}_{2} \mathrm{C}_{2} \mathrm{O}_{4}$ in $0.01 \mathrm{M} \mathrm{HNO}_{3} \ldots 21$

Table 10: Zirconium and Americium Extraction Distribution Coefficients

as a Function of CMP Concentration .................. 23

Table 11: Uranium and Plutonium Distribution Coefficients Using $0.5 \mathrm{M}$ CMP . . . . . 26

Table 12: $D_{C_{r}}$ for Extraction, Scrub, Strip, and Wash Contacts ............. 28

Table 13: $\mathrm{Zr}$, Tc, and Actinide Extraction into $0.5 \mathrm{M} \mathrm{CMP}$ from Reduced Run 74

Feeds .............................. 31

Table 14: Scrub Distribution Coefficients from $0.5 \mathrm{M}$ CMP Using

$0.05 \mathrm{M} \mathrm{H}_{2} \mathrm{C}_{2} \mathrm{O}_{4}$ in $3.0 \underline{\mathrm{M}} \mathrm{HNO}_{3} \ldots \ldots \ldots \ldots \ldots \ldots \ldots \ldots \ldots \ldots \ldots \ldots \ldots \ldots$

Table 15: Strip Distribution Coefficients from $0.5 \underline{\mathrm{M}} \mathrm{CMP}$ using $0.001 \underline{\mathrm{M}}$ HEDPA . . . 34 


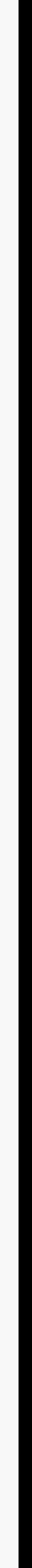




\section{INTRODUCTION}

Actinide separation processes are being evaluated at the Idaho Chemical Processing Plant (ICPP) to minimize the volume of high-level radioactive waste requiring disposal in a geological repository. A solvent extraction process using dihexyl-N,N-diethylcarbamoylmethyl phosphonate (CMP) as the primary actinide extractant is being evaluated at the ICPP to separate the actinides from the high activity calcines and sodium-bearing waste (SBW). The goal of actinide separation processes applied to these two wastes is a resulting aqueous raffinate stream that meets the 10 CFR 61.55 Class A transuranic (TRU) waste limit of $<10 \mathrm{nCi} / \mathrm{g}$. The purpose of this document is to report the results of applying the CMP extractant to ICPP dissolved zirconium pilot-plant calcine. Extraction, scrub, and strip distribution coefficients of the actinides, $\mathrm{Zr}, \mathrm{Cr}$, and $\mathrm{Tc}$ were obtained from batch contacts with the dissolved pilot-plant zirconium calcine. These distribution coefficients, as well as the physical characteristics of the CMP solvent, will eventually be compared to other solvent extraction processes (TRUEX). Data generated from this study will be used to recommend a flowsheet for testing in a $5.5 \mathrm{~cm}$ Centrifugal Contactor Mock-up located at the ICPP and to satisfy some of the criteria for selecting a solvent extraction process for treating ICPP calcines.

Approximately $3,800 \mathrm{~m}^{3}$ of high-level waste ( $\mathrm{HLW}$ ) calcine was generated from aluminum and zirconium fuel reprocessing raffinates and is currently stored at the ICPP [1]. The calcine is primarily made-up of inert metal oxides $\left(\mathrm{Al}_{2} \mathrm{O}_{3}, \mathrm{ZrO}_{2}\right.$, and $\left.\mathrm{CaO}\right)$ and $\mathrm{CaF}_{2}$ [2]. Fluoride is present in these raffinates from the addition of $\mathrm{HF}$ and $\mathrm{HBF}_{4}$ during the dissolution of zirconium fuels and can volitilize as HF during calcination. HF is very corrosive to calcination equipment; therefore, calcium was added to some of the raffinates prior to calcination to inhibit fluoride (HF) volatility. TRU and fission product concentrations in the calcine are less than $1 \mathrm{wt} \%$ [3]. A significant volume reduction may be achieved if these radioactive constituents are partitioned from the non-radioactive components of the calcine, as opposed to direct disposal (vitrification) of this material.

Calcine used in the evaluation of the CMP solvent was generated in the $30-\mathrm{cm}$ pilot- 
plant calciner at the ICPP in February, 1979. This calcine is here after designated as Run 74 calcine which was generated from a simulated blend of wastes from tanks WM-188 and WM189. Waste in these tanks were similar in composition; therefore, no blend ratios were performed. These tanks contained a combination of first-cycle zirconium raffinate and stainless steel sulfate waste diluted with non-fluoride wastes. Run 74 calcine was generated to evaluate the calcination of WM-188 and WM-189 tank wastes at the Waste Calcination Facility (WCF).

Run 74 calcine was chosen as a suitable waste simulant for radionuclide separations testing because it is similar to actual ICPP zirconium calcine. Actual ICPP zirconium calcine represents approximately $3,000 \mathrm{~m}^{3}$ of the current $3,800 \mathrm{~m}^{3}$ inventory [4]. ICPP zirconium calcines are expected to be the most challenging with regards to actinide separation flowsheet development because of their high zirconium, calcium, and fluoride content. Zirconium has historically presented problems by coextracting with the TRU elements. Zirconium extraction may result in physical problems associated with the solvent, such as third phase formation or interfacial crud. Zirconium recovery with the actinides may increase the volume of final high-level waste. Inhibiting zirconium extraction can be accomplished with complexing agents but high calcium concentrations, present in dissolved solutions of zirconium calcine, typically form undesirable insoluble salts with these complexants. Zirconium complexing agents may also prevent the extraction of the actinides to such an extent as to exceed the Class A TRU waste limit of $10 \mathrm{nCi} / \mathrm{g}$ in the aqueous raffinate. Successful actinide separations flowsheet development with the zirconium calcine would potentially result in a flowsheet applicable to the total ICPP calcine inventory.

A significant effort has been devoted at the ICPP to develop calcine dissolution flowsheets that result in feeds suitable for aqueous separation processes [4-7]. Suitable calcine solutions are defined as those that: 1) contain the smallest concentration of undissolved solids, 2) are stable with respect to precipitate formation after dissolution and after contact with the extractant, and 3) provide adequate actinide distribution coefficients with no (or a minimal amount of) feed adjustments. Dissolution parameters defined by Herbst, et al., [5] were used to dissolve the Run 74 pilot-plant calcine. 
The dissolution parameters established by Herbst [5], were also evaluated on actual zirconium calcine [4]. Greater than $95 \mathrm{wt} \%$ of the calcine was dissolved and the resulting dissolved calcine solution had an approximate total alpha activity of $1250 \mathrm{nCi} / \mathrm{g}$. The contribution of the individual TRUs to this activity are shown in Table 1.

Table 1: TRU Activity in Actual Dissolved Zirconium Calcine

\begin{tabular}{|c|c|c|c|c|}
\hline \hline Isotope & Am-241 & Pu-238 & Pu-239 & Np-237 \\
\hline Activity (nCi/g) & 104 & 1100 & 42 & 0.5 \\
\hline
\end{tabular}

The total alpha activity in some dissolved calcine solutions could be as large as 10,000 $\mathrm{nCi} / \mathrm{g}$. Taking the range of 1,000 to $10,000 \mathrm{nCi} / \mathrm{g}$ total alpha into consideration, a TRU activity removal between $99 \%$ and $99.9 \%$ is required for the aqueous raffinate to contain $<10$ nCi/g total alpha activity. 
is a surprising result, since McIsaac [8] reported the $\mathrm{D}_{\mathrm{zr}}=0.018$ in a test with zirconium fuel reprocessing raffinate simulant, indicating that small amounts of extracted zirconium may cause physical problems with the solvent.

The mixer-settler test was repeated by Baker and co-workers [10], but this time two of the mixer-settler stages in the hot cell were used to concurrently scrub the loaded solvent and the remaining six stages were used for extraction. The solvent was scrubbed with $3 \underline{\mathrm{M}} \mathrm{HNO}_{3}$ to remove the extracted zirconium. This eliminated the zirconium precipitation. Americium and plutonium decontamination factors of 170 and 2500 were achieved in this test. Greater

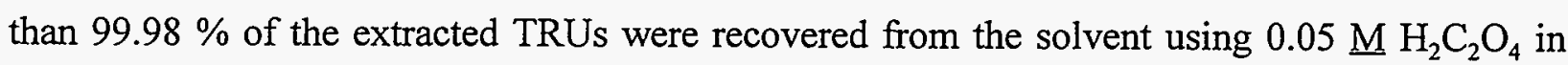
$0.005 \underline{\mathrm{M} \mathrm{HNO}}$; however, a white precipitate formed in the first stripping stage after several 


\section{EXPERIMENTAL}

\section{Run 74 Calcine Feed}

Run 74 calcine was dissolved according to the procedure developed by Herbst, et al. [5]. Herbst's work was scaled-up to evaluate those dissolution parameters defined in the small scale testing and to generate a large volume of dissolved Run 74 calcine for radionuclide separations testing. Dissolved Run 74 calcine generated in the dissolution pilotplant was used as the dissolved calcine feed tested in this study. A 60:40 wt.\% mixture of Run 74 calcine product and fines was dissolved at $90^{\circ} \mathrm{C}$ in $5 \underline{\mathrm{M}} \mathrm{HNO}_{3}$. One liter of $5 \underline{\mathrm{M}}$ $\mathrm{HNO}_{3}$ was added to every $100 \mathrm{gm}$ of the product:fines mixture. Approximately $1 \mathrm{~kg}$ of the product:fines mixture was dissolved per batch. Each batch was allowed to be in contact with the hot acid for a minimum of 30 minutes while being well mixed. Approximately $200 \mathrm{~L}$ of dissolved Run 74 calcine feed were generated. Dissolved Run 74 calcine feed composition is shown in Table 2.

The feed was clarified by filtering through a $0.45 \mu \mathrm{m}$ cellulose nitrate filter prior to testing. Tests were performed directly with the clarified feed, or with the clarified feed reduced with hydrogen peroxide prior to contact with the CMP solvent. Hydrogen peroxide was used to reduce $\mathrm{Cr}(\mathrm{VI})$ to $\mathrm{Cr}(\mathrm{III})$. Feed reduction was performed by "titrating" a specified feed volume with $30 \% \mathrm{H}_{2} \mathrm{O}_{2}$ until the feed color changed from yellow $\{\mathrm{Cr}(\mathrm{VI})\}$ to blue $\{\mathrm{Cr}(\mathrm{III})\}$. Less than $100 \mu \mathrm{L}$ of $30 \% \mathrm{H}_{2} \mathrm{O}_{2}$ was required to reduce $100 \mathrm{~mL}$ of feed. Holding reductants were not added to the feed because of the stability of $\mathrm{Cr}(\mathrm{III})$. The reduced feed was allowed to stand for 24 hours before use.

\section{Reagents/Chemicals}

Approximately $20 \mathrm{~L}$ of CMP was obtained from Sandia National Laboratory. The history of this CMP is unknown and is suspected to contain some organic impurities. Three CMP solvent concentrations were evaluated, $0.75 \underline{\mathrm{M}}, 0.5 \underline{\mathrm{M}}$, and $0.25 \underline{\mathrm{M}} \mathrm{CMP}$, all in $1.0 \underline{\mathrm{M}}$ 
Table 2: Dissolved Run 74 Calcine Feed Composition

\begin{tabular}{|c|c|c|}
\hline Element & $\begin{array}{c}\mathrm{wt} \% \text { in calcine } \\
\text { before dissolution }\end{array}$ & $\begin{array}{c}\text { Feed concentration } \\
\underline{M}\end{array}$ \\
\hline $\mathrm{Al}$ & 11.2 & $4.2 \mathrm{E}-1$ \\
\hline B & 1.1 & $6.8 \mathrm{E}-2$ \\
\hline $\mathrm{Ca}$ & 25.0 & $6.5 \mathrm{E}-1$ \\
\hline $\mathrm{Ce}$ & 0.1 & $4.0 \mathrm{E}-4$ \\
\hline $\mathrm{Cr}$ & 0.4 & 5.7E-3 \\
\hline $\mathrm{Cs}$ & 0.5 & 4.7E-3 \\
\hline $\mathrm{Fe}$ & 0.1 & $1.3 \mathrm{E}-2$ \\
\hline $\mathrm{K}$ & $<0.1$ & $6.0 \mathrm{E}-4$ \\
\hline Mo & ND & $1.8 \mathrm{E}-4$ \\
\hline $\mathrm{Na}$ & 0.4 & $8.5 \mathrm{E}-3$ \\
\hline $\mathrm{Ni}$ & 0.1 & $1.7 \mathrm{E}-3$ \\
\hline $\mathrm{Pb}$ & $<0.1$ & $<1.9 \mathrm{E}-6$ \\
\hline $\mathrm{Sr}$ & 0.7 & $8.1 \mathrm{E}-3$ \\
\hline $\mathrm{Zr}$ & 16.6 & $2.1 \mathrm{E}-1$ \\
\hline $\mathrm{Cl}^{-}$ & $<0.2$ & $<8.8 \mathrm{E}-2$ \\
\hline $\mathrm{F}^{-}$ & 17.4 & $8.9 \mathrm{E}-1$ \\
\hline $\mathrm{H}^{+}$ & NA & 3.5 \\
\hline $\mathrm{NO}_{3}^{-}$ & $<0.1$ & 6.0 \\
\hline $\mathrm{PO}_{4}^{-3}$ & ND & ND \\
\hline $\mathrm{SO}_{4}^{-2}$ & 5.4 & $5.0 \mathrm{E}-2$ \\
\hline density & NA & 1.2 \\
\hline
\end{tabular}

NA = Not Applicable

$\mathrm{ND}=$ Not Determined

1. Remainder of mass balance is oxygen 
TBP and an Isopar $\mathrm{L}^{\otimes}$ diluent. This range of CMP concentrations were chosen based on the hydraulic parameters of the $5.5-\mathrm{cm}$ Centrifugal Contactor Mockup. A solvent containing 0.75 $\underline{\mathrm{M}} \mathrm{CMP}, 1.0 \underline{\mathrm{M}} \mathrm{TBP}$ in an Isopar $\mathrm{L}^{\otimes}$ diluent resulted in flooding problems when tested in the $5.5 \mathrm{~cm}$ Centrifugal Contactor Mockup with an ICPP sodium-bearing waste simulant [13]. The flooding problems were eliminated when the CMP concentration in the solvent was reduced to $0.5 \underline{\mathrm{M}}$.

Technical grade TBP (Baker Chem., Inc.) was used as a phase modifier in the solvent. Isopar $\mathrm{L}^{\circledast}$ (Exxon Chemical Co.), a branched chain hydrocarbon, was chosen as the diluent, as opposed to a normal paraffinic hydrocarbon (NPH), because it appears to be more effective at preventing third phase formation. Some third phase formation was observed when the TRUEX solvent (containing n-dodecane as the diluent) was contacted with the Run 74 dissolved calcine. The third phase was eliminated when the diluent was changed to Isopar $L^{\otimes}$. The Isopar $L^{\circledast}$ diluent was chosen as the CMP diluent because of the experience with $n$ dodecane in the TRUEX solvent and Run 74 calcine [11]. The CMP solvent was prepared by the Quality Control (QC) Laboratory at the ICPP and was washed with three contacts of 0.25 $\underline{\mathrm{M} \mathrm{Na}} \mathrm{CO}_{3}(\mathrm{O} / \mathrm{A}=5)$ prior to testing.

The gross strip reagent, 1-hydroxyethane-1,1-diphosphonic acid (HEDPA), was obtained from Albright \& Wilson. Solutions of HEDPA were prepared by the QC Laboratory. Ammonium fluoride and oxalic acid scrub solutions were also prepared by the QC Laboratory.

The $\mathrm{Zr}-95$ tracer was obtained from Isotope Products Laboratories and was received in $1 \mathrm{M} \mathrm{H} \mathrm{H}_{2} \mathrm{C}_{2} \mathrm{O}_{4}$. Two $\mathrm{Zr}-95$ tracers were used during this study. The first $\mathrm{Zr}-95$ tracer $(\sim 5.4 \mu \mathrm{Ci}$ in $5 \mathrm{~mL}$ ) was diluted to $100 \mathrm{~mL}$ with $2 \underline{\mathrm{M}} \mathrm{HNO}_{3}$. No attempt was made to destroy the oxalate in the tracer stock solution because the concentration of oxalate in the spiked Run 74 feeds was typically $0.005 \underline{\mathrm{M}}$, compared to $0.2 \mathrm{M}$ total $\mathrm{Zr}$. Minimal zirconium complexing by oxalate would occur under these conditions. The second $\mathrm{Zr}-95$ tracer was prepared by destroying the oxalate before use. The as recieved $\mathrm{Zr}-95$ standard solution was evaporated to dryness and redissolved in $10 \mathrm{mLs}$ of concentrated nitric acid. This solution was again evaporated to dryness. Oxalate solids were then destroyed by adding $0.5 \mathrm{~mL}$ of $30 \% \mathrm{H}_{2} \mathrm{O}_{2}$ 
while the solids were still hot. The solids immediately disappeared. The $\mathrm{Zr}-95$ was redissolved in $6 \underline{\mathrm{M}} \mathrm{HNO}_{3}$ and re-evaporated to verify the absence of oxalate in the tracer. Finally, $2 \mathrm{M} \mathrm{HNO}_{3}$ was used to bring the tracer to a volume of $50 \mathrm{mLs}$. This tracer solution was used in all tests with $0.5 \mathrm{M}$ CMP.

Am-241 tracer was obtained from Argonne National Laboratory. The Am-241 was dissolved in $1 \%$ nitric acid and brought up to a total volume of $100 \mathrm{~mL}$. Am-241 activity in the stock solution was $1.69 \mathrm{E}+5 \mathrm{dps} / \mathrm{mL}$. Np-239 was obtained in pure form from the ICPP's Isotopic Measurement Systems group by "milking" Np-239 from an Am-243 "cow" (Am-243 absorbed onto a cation exchange column). The Np-239 was eluted from the column with $\mathrm{HIO}_{4}$ and $\mathrm{HCl}$ and converted to the nitrate form by evaporating to dryness twice in $\mathrm{HNO}_{3}$. Residual americium was removed from the Np-239 tracer by passing the tracer through a TRU-Spec ${ }^{\circledR}$ column. Americium was retained on the column while a majority of the neptunium passed through. The absence of Am-241 and Am-243 was verified in the $\mathrm{Np}$ tracer by gamma spectroscopy.

U-233 tracer was prepared from a New Brunswick Certified Reference Material (CRM 111-A). The Th-229 daughter was separated from the U-233 by passing the tracer through an Aliquat $336 \mathrm{~N}$ column. The radium daughter was removed from the U-233 by performing two sequential co-precipitations with $\mathrm{BaSO}_{4}$. The U-233 standard was analyzed by gamma spectroscopy and by liquid scintillation counting (LSC) following purification to verify the absence of Th-229. The standard was counted by LSC at two and four week intervals to ensure absence of the radium daughter. Counting values obtained at these intervals agree with the initial activity determined by LSC following purification.

Pu-238 and Tc-99 tracers were obtained from the Radiochemistry Group at the ICPP and were used as made-up.

\section{Experimental Methodology}

Run 74 dissolved calcine spiked with a single radioactive isotope was typically tested. The only exception being tests conducted with Am-241 and Zr-95, which were tested together 
because both isotopes have resolvable gamma energies. Isotopes were spiked into the feed 24 to 48 hours before contacting with the CMP solvent. Reduced feeds were prepared by reducing the feed twenty-four hours after addition of the tracer to the feed. The twenty-four hour interval between tracer addition and feed reduction allowed the tracer to reach an equilibrium oxidation state with the initial feed. Allowing the tracer to reach equilibrium in the reduced feed by permitting that feed to stand for an additional 24 hours before contacting with the CMP solvent provided time for the tracer to again reach equilibrium conditions. Effects of feed reduction on the TRUs being evaluated was considered to be more representative of actual waste processing conditions when performed in this manner.

The CMP solvent was pre-equilibrated three times with a tracer free feed prior to contact with the traced feed except in those tests involving Zr-95. Reduced, non-traced feed was used to pre-equilibrate the solvent when tests were performed with reduced feed. When $\mathrm{Zr}-95$ traced feed (either reduced or non-reduced) was to be contacted with the CMP solvent, the solvent was pre-equilibrated with $3.4 \mathrm{M} \mathrm{HNO}_{3}$. Acid was used instead of tracer free feed to prevent the extraction of stable zirconium into the solvent while still loading the solvent with acid. Pre-equilibrating the solvent prior to contacting with the traced feed allows for the measurement of distribution coefficients under close to equilibrium conditions by minimizing perturbations of the distribution coefficient caused by the extraction of acid or other species.

Single batch, equal-volume contacts of the aqueous and organic phases were performed. Both phases were sampled after the phases were contacted for 1 minute on a vortex mixer and centrifuged for five minutes at 3500 RPM. All tracer tests were performed at $25^{\circ} \mathrm{C} \pm 2^{\circ} \mathrm{C}$. A schematic of the experimental procedure used in this study is shown in Figure 1.

Three extraction, scrub, and strip contacts were performed. Extraction contacts are designated E1-E3, scrub contacts Sc1-Sc3, and strip contacts St1-St3. Two wash contacts W1 and W2 were performed in some tests. Several scrub and strip solutions were evaluated during this testing. 


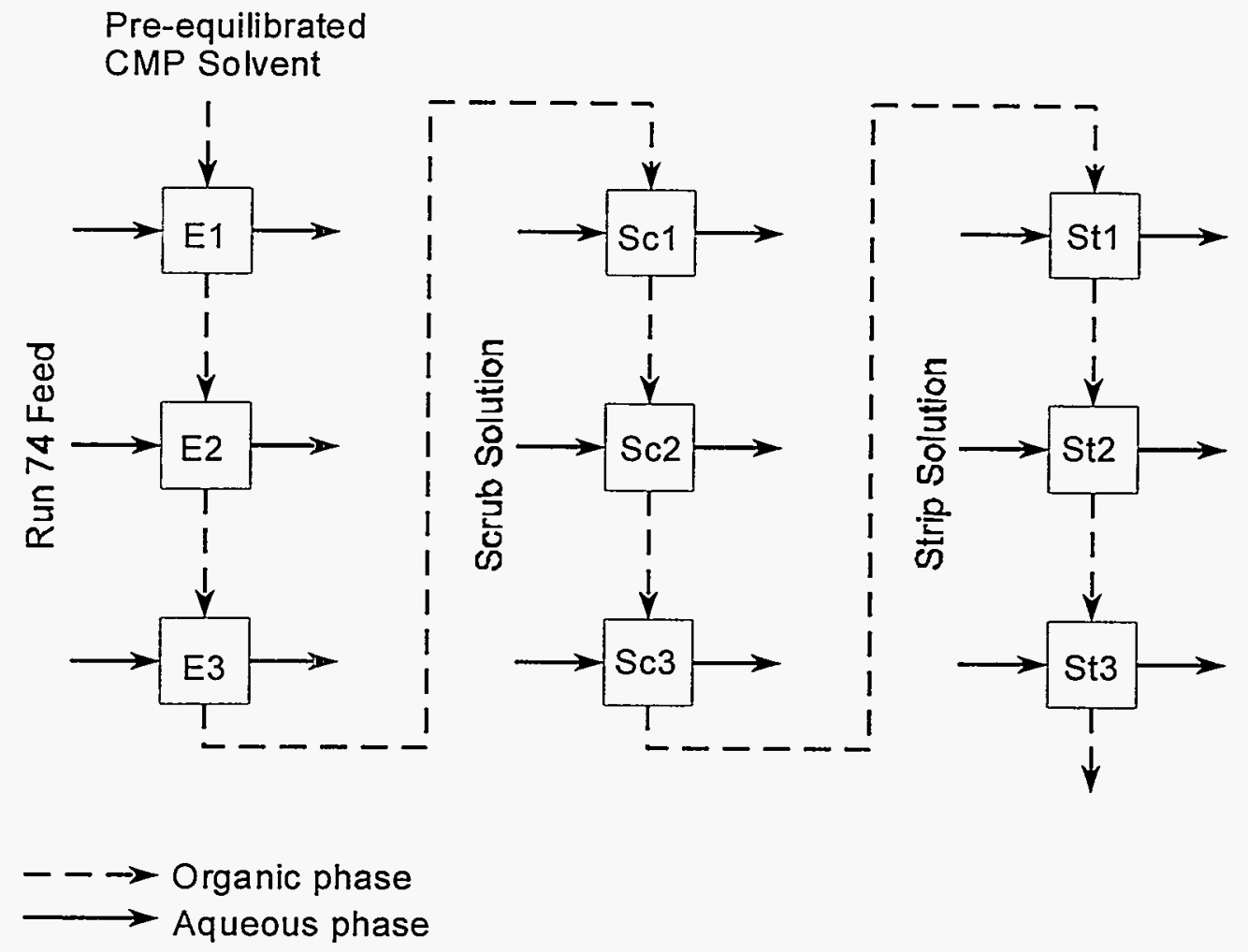

Figure 1: Experimental Procedure used for testing Simulated ICPP Dissolved Zirconium Calcine

\section{Analytical Methods}

Zr-95 and Am-241 analyses were performed by gamma spectroscopy using a high purity p-type coaxial germanium detector rated at $80 \%$ relative efficiency. The $59.5 \mathrm{keV}$ photopeak was used to determine the Am-241 activity for all samples containing mixed isotopes of zirconium and americium. Zr-95 activities were determined from the $756.7 \mathrm{keV}$ photopeak. Niobium-95, daughter of Zr-95 can potentially cause interferences with analysis 
of $\mathrm{Zr}-95$. Nb-95 primary energy is located at $765.8 \mathrm{keV}$. However, evaluating the $\mathrm{Zr}-95$ activity using its $724 \mathrm{keV}$ gamma energy as a confirmatory measurement produced results within $1 \%$ of those determined using the $756.7 \mathrm{keV}$ energy. This indicates that scattering events or any other possible spectral interferences did not cause a bias in the $\mathrm{Zr}-95$ at its primary energy. All $\mathrm{Zr}-95$ results were decay corrected to the feed count time because of the short Zr-95 half-life (64 days). All samples were counted in sealed vials which were loaded onto a sample autochanger which included a large background shield around the gamma detector. The detector was calibrated for this geometry using a $1 \mathrm{ml}$ mixed radionuclide NIST-traceable standard. Quality control was monitored by counting a traceable point source before, during, and after the sequence of sample counts.

Liquid Scintillation Counting (LSC) was used to determine activities of samples containing single isotopes. LSC spectrometry is a gross activity measurement since it has no capability to resolve emissions of different energies. A xylene "cocktail" was added to $1 \mathrm{~mL}$ aqueous and organic samples. Aqueous and organic blanks were prepared with each sample set. Blank activities were subtracted from the total sample activity prior to determining distribution coefficients for a given contact. The samples were counted on a Packard Bell LS 6000 . 


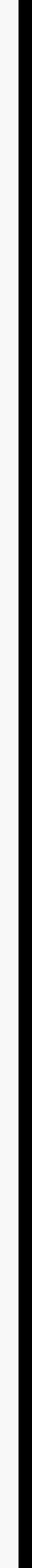




\section{RESULTS/DISCUSSION}

Several tracer tests were conducted to select: 1) solvent composition, 2) scrub reagent, 3) gross actinide stripping reagent, and 4) optimized scrub and strip concentrations. Batch contacts were conducted to develop a flowsheet for treating actual dissolved calcine. Results from batch contact tests with spiked Run 74 dissolved calcine feed were used in the Generic TRUEX Model (GTM) to simulate counter-current process conditions. GTM results were used to validate the recommended flowsheet for scale-up testing in the $5.5-\mathrm{cm}$ Centrifugal Contactor Mockup.

\section{$0.75 \underline{M}$ CMP Tests}

Initial testing with the CMP solvent was performed using the CMP and TBP concentrations described by Rapko and Lumetta [14] (0.75 M CMP and 1.0 M TBP). Rapko and Lumetta [14] used a straight chain hydrocarbon as the diluent; Isopar $\mathrm{L}^{\circledast}$, a branched chain hydrocarbon, was used in these tests. Tracer tests were performed by spiking the clarified non-reduced Run 74 calcine with either Zr-95, Tc-99, U-233, Np-239, Pu-238, or Am-241. The spiked Run 74 feed was contacted with pre-equilibrated CMP solvent after the feed itself was allowed to equilibrate for at least 24 hours. Table 3 shows the extraction distribution coefficients for contacts, E1, E2, E3; where the solvent was contacted three times with fresh spiked feed being used for each contact.

Table 3: Extraction Distribution Coefficients Using $0.75 \underline{\mathrm{M}} \mathrm{CMP}$ and $1.0 \underline{\mathrm{M}}$ TBP in Isopar $\mathrm{L}^{\circledR}$

\begin{tabular}{|c|c|c|c|c|c|c||}
\hline Contact & $\mathrm{D}_{\mathrm{Zr}}$ & $\mathrm{D}_{\mathrm{Tc}}$ & $\mathrm{D}_{\mathrm{U}}$ & $\mathrm{D}_{\mathrm{Pu}}$ & $\mathrm{D}_{\mathrm{Np}}$ & $\mathrm{D}_{\mathrm{Am}}$ \\
\hline $\mathrm{E} 1$ & 0.24 & 0.88 & 242 & 81 & $>133$ & 15 \\
\hline $\mathrm{E} 2$ & 0.26 & 0.91 & 265 & 91 & 280 & 15 \\
\hline $\mathrm{E} 3$ & 0.29 & 0.92 & 265 & 96 & 350 & 15 \\
\hline
\end{tabular}


Desirably large uranium and TRU extraction distribution coefficients were achieved with this solvent composition, while a small extraction distribution coefficient for zirconium was also observed $\left(D_{Z_{r}}<0.3\right)$. Less than $20 \%$ of the zirconium extracted in the first extraction contact $\mathrm{E} 1$, while $>98 \%$ of the $\mathrm{Pu},>99 \%$ of the $\mathrm{Np}$, and $>90 \%$ of the Am extracted in this contact. Uranium was also quantitatively extracted (>99\%).

The large $D_{\mathrm{Np}}$ obtained in all three extraction contacts is interesting. Even though neptunium is a minor contributor to the total alpha activity in the calcine (Table 1), these large distribution coefficients were not expected and should be explained. H. R. Maxey, et. al., [15] reports $\mathrm{Np}(\mathrm{IV})$ and $\mathrm{Np}(\mathrm{VI})$ distribution coefficients from solutions of pure nitric acid into $30 \% \mathrm{CMP}(\sim 0.7 \underline{\mathrm{M}} \mathrm{CMP})$ in diisopropylbenzene (DIPB). Maxey reports distribution

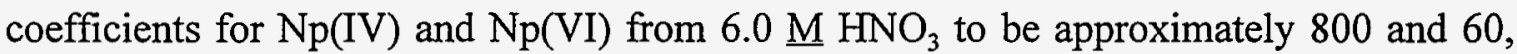
respectively. Krupa, et. al. [16], performed tests with simulated zirconium-aluminum fuel coprocessing waste and $20 \% \mathrm{CMP}$ in DIPB. The simulated waste used by Krupa was $1.5 \underline{\mathrm{M}}$ $\mathrm{HNO}_{3}$ and $2.4 \mathrm{M}$ total $\mathrm{NO}_{3}^{-}$. Krupa reports a distribution coefficient for $\mathrm{Np}(\mathrm{V})$ of $\mathrm{D}_{\mathrm{Np}}=0.55$ [16]. Based on the $\mathrm{Np}$ distribution coefficients reported by Maxey and Krupa, and the $\mathrm{D}_{\mathrm{Np}}$ shown in Table 3, it would appear that neptunium is partitioned between the +4 and +6 oxidation states in the dissolved Run 74 zirconium calcine. Neptunium added to the Run 74 feed was expected to be in the +5 oxidation state; not partitioned between the +4 and +6 oxidation states.

Katz, Seaborg, and Morss report that $N p(V)$ is oxidized to $N p(V I)$ by nitric acid containing small amounts of nitrite $\left(\mathrm{NO}_{2}{ }^{-}\right)$[17]. Nitrite in turn can reduce $\mathrm{Np}(\mathrm{VI})$ to $\mathrm{Np}(\mathrm{V})$. The mechanism for the oxidation-reduction reaction for neptunium by nitric acid and nitrite is shown in Equation 1.

$$
\mathrm{NpO}_{2}^{+}+3 / 2 \mathrm{H}^{+}+1 / 2 \mathrm{NO}_{3}^{-} \rightleftharpoons \mathrm{NpO}_{2}^{+2}+1 / 2 \mathrm{HNO}_{2}+1 / 2 \mathrm{H}_{2} \mathrm{O}
$$

The equilibrium of Equation 1 is shifted to the right during solvent extraction processes because $\mathrm{NpO}_{2}^{+2}$ is preferentially extracted over $\mathrm{NpO}_{2}^{+}$. The large acid concentration in Run 74 dissolved calcine feed may be enough to shift the equilibrium to the right during 
contacts with the CMP solvent resulting in significant $\mathrm{Np}(\mathrm{VI})$ extraction. However, a comparison of Maxey's data to $D_{\mathrm{Np}}$ shown in Table 3 would indicate the presence of $\mathrm{Np}$ (IV) in the dissolved Run 74 feed. Katz also describes the partitioning of $\mathrm{Np}(\mathrm{V})$ to $\mathrm{Np}(\mathrm{IV})$ and $\mathrm{Np}(\mathrm{VI})$ in highly acidic solutions [17]. This partitioning is shown in Equation 2.

$$
2 \mathrm{NpO}_{2}^{+}+4 \mathrm{H}^{+} \rightleftharpoons \mathrm{Np}+4+\mathrm{NpO}_{2}^{+2}+2 \mathrm{H}_{2} \mathrm{O}
$$

Partitioning of $N p(V)$ to $N p(I V)$ and $N p(V I)$ in highly acidic solutions may also provide a plausible explanation for the large $D_{\mathrm{Np}}$ shown in Table 3. A combination of the mechanisms shown in Equations 1 and 2 is also likely.

The extraction distribution coefficients shown in Table 3 indicate that uranium and the TRUs will be removed from zirconium calcine feeds to below the $10 \mathrm{CFR} 61.55$ Class A non-TRU waste limit. Technetium's extraction distribution coefficient is expected to be large enough to partially remove Tc-99 from the dissolved calcine feed. This will have to be confirmed by performing counter-current tests with actual dissolved calcine since a suitable non-radioactive $T c$ surrogate has not been found to predict $T c$ behavior in the $5.5-\mathrm{cm}$ Centrifugal Contactor Mockup. Even though $\mathrm{D}_{\mathrm{zr}}$ is desirably small, a significant mass of zirconium will extract with the actinides. If the extracted zirconium is allowed to be stripped with the actinides, a drastic increase in the final HLW glass or glass-ceramic waste volume may occur. The lack of success in preventing zirconium extraction necessitated the need to scrub zirconium from the solvent without causing significant actinide recycle (specifically for Am-241).

Zirconium scrubbing tests were performed using the $0.75 \mathrm{M}$ CMP solvent loaded with Zr-95 and Am-241 from three successive contacts with the spiked Run 74 feed. Stable zirconium from the feed was also extracted. The loaded solvent was then contacted with either $0.05 \mathrm{M} \mathrm{H}_{2} \mathrm{C}_{2} \mathrm{O}_{4}$ in $3 \underline{\mathrm{M}} \mathrm{HNO}_{3}$ or $1.5 \mathrm{M} \mathrm{HNO}_{3}$. These scrub compositions were chosen based on the work performed by Baker [10] and on $\mathrm{D}_{\mathrm{Am}}$ as a function of $\left[\mathrm{HNO}_{3}\right]$ using 0.75 M CMP [18]. Table 4 shows the results from $\mathrm{Zr}$ and Am scrubbing tests. 


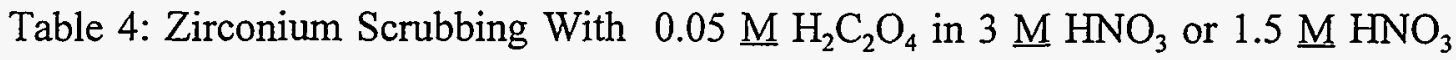

\begin{tabular}{||c|c|c|c|c|c|c||}
\hline & \multicolumn{2}{|c|}{$0.05 \underline{\mathrm{M} \mathrm{H}_{2} \mathrm{C}_{2} \mathrm{O}_{4} \text { in } 3 \mathrm{M} \mathrm{HNO}_{3}}$} & \multicolumn{3}{|c||}{$1.5 \mathrm{M} \mathrm{HNO}_{3}$} \\
\hline & $\mathrm{Sc1}$ & $\mathrm{Sc} 2$ & $\mathrm{Sc} 3$ & $\mathrm{Sc} 1$ & $\mathrm{Sc} 2$ & $\mathrm{Sc} 3$ \\
\hline $\mathrm{D}_{\mathrm{Zr}}$ & 0.054 & $<<1$ & $\mathrm{NA}$ & 0.26 & 0.29 & 1.18 \\
\hline $\mathrm{D}_{\mathrm{Am}}$ & 7.05 & 7.39 & 7.49 & 5.58 & 4.02 & 3.74 \\
\hline
\end{tabular}

$\mathrm{NA}=$ No detectable activity in either phase

Dilute ammonium fluoride $\left(0.1 \mathrm{M} \mathrm{NH}_{4} \mathrm{~F}\right)$ was also evaluated as a zirconium scrub reagent. Uranium, plutonium, americium, and zirconium were extracted into the CMP solvent from spiked Run 74 feed. The loaded solvent was then contacted three times with equal and fresh volumes of $0.1 \mathrm{M} \mathrm{NH} \mathrm{F}_{4}$ in $3 \mathrm{M} \mathrm{HNO}_{3}$. Results from this test are shown in Table 5.

Table 5: Zirconium and Actinide Scrubbing With $0.1 \underline{\mathrm{M} \mathrm{NH}} \mathrm{N}_{4}$ in $3 \underline{\mathrm{M}} \mathrm{HNO}_{3}$

\begin{tabular}{||c|c|c|c|c||}
\hline \hline Contact & $\mathrm{D}_{\mathrm{U}}$ & $\mathrm{D}_{\mathrm{Pu}}$ & $\mathrm{D}_{\mathrm{Am}}$ & $\mathrm{D}_{\mathrm{Zr}}$ \\
\hline $\mathrm{Sc} 1$ & 23.1 & 93.7 & 8.06 & 0.027 \\
\hline $\mathrm{Sc} 2$ & 5.30 & 45.1 & 6.81 & 0.77 \\
\hline $\mathrm{Sc} 3$ & 4.94 & 39.3 & 6.73 & $<1$ \\
\hline
\end{tabular}

The $0.05 \mathrm{M} \mathrm{H}_{2} \mathrm{C}_{2} \mathrm{O}_{4}$ in $3 \underline{\mathrm{M}} \mathrm{HNO}_{3}$ scrub solution was found to be more effective than $1.5 \mathrm{M} \mathrm{HNO}_{3}$ at removing zirconium from the solvent while also minimizing americium recycle $\left(\mathrm{D}_{\mathrm{Am}}\right.$ is larger in the oxalic acid scrub contacts). The increase in $\mathrm{D}_{\mathrm{zr}}$ in the final scrub contact, Sc3, may be due to solvent impurities. Dilute ammonium fluoride results are comparable to the those obtained with dilute oxalic acid, and should be considered as a viable scrub reagent. The uranium scrub distribution coefficients are smaller than desired with the $0.1 \mathrm{M} \mathrm{NH} \mathrm{NH}_{4}$ but $\mathrm{D}_{\mathrm{U}}$ could be increased in the scrub section by optimizing (decreasing) the $\mathrm{NH}_{4} \mathrm{~F}$ concentration. Uranium concentrations in the dissolved calcine feed are expected to be minimal since uranium separation processes were performed on these solutions prior to calcination. Therefore, the small scrub $\mathrm{D}_{\mathrm{U}}$ may be of little consequence. The $\mathrm{NH}_{4} \mathrm{~F}$ 
concentration evaluated in this test could possibly be decreased below $0.1 \underline{\mathrm{M}}$ and still quantitatively remove zirconium from the solvent.


scrub distribution coefficients of $\mathrm{U}, \mathrm{Pu}, \mathrm{Np}$, and $\mathrm{Tc}$. Again, the CMP solvent that was contacted three times with Run 74 dissolved calcine spiked with either U-233, Pu-238, Np239 , or Tc-99 was contacted three times with equal volumes of $0.05 \mathrm{M} \mathrm{H}_{2} \mathrm{C}_{2} \mathrm{O}_{4}$ in $3 \mathrm{M} \mathrm{HNO}_{3}$. Scrub distribution coefficients from this test are shown in Table 6.

Table 6: Technetium and Actinide Scrub D's Using $0.05 \underline{\mathrm{M}} \mathrm{H}_{2} \mathrm{C}_{2} \mathrm{O}_{4}$ in $3 \underline{\mathrm{M}} \mathrm{HNO}_{3}$

\begin{tabular}{||c|c|c|c|c||}
\hline Contact & $\mathrm{D}_{\mathrm{U}}$ & $\mathrm{D}_{\mathrm{Pu}}$ & $\mathrm{D}_{\mathrm{Np}}$ & $\mathrm{D}_{\mathrm{Tc}}$ \\
\hline $\mathrm{Sc} 1$ & 106 & 31.4 & 77.2 & 1.74 \\
\hline $\mathrm{Sc} 2$ & 90.5 & 24.0 & 58.5 & 2.12 \\
\hline $\mathrm{Sc} 3$ & 86.2 & 22.9 & 32.7 & 2.20 \\
\hline
\end{tabular}

Scrub distribution data shown in Table 6 indicate that very little actinide or technetium loss will occur with the $0.05 \mathrm{M} \mathrm{H}_{2} \mathrm{C}_{2} \mathrm{O}_{4}$ in $3 \mathrm{M} \mathrm{HNO}_{3}$ scrub solution. This scrub solution would appear to be effective at accomplishing the goal of selectively removing zirconium while minimizing actinide recycle. The only concern with this scrub solution is the formation of precipitates when combined with the aqueous feed. These precipitates will not only reduce contactor performance but may also carry down actinides. Previous tests have shown that a small amount of oxalate in the feed may result in a visible calcium oxalate precipitate. Reduced contactor performance and precipitates containing actinides may result in aqueous raffinates contaminated with TRUs above the 10 CFR 61.55 Class A limit of $10 \mathrm{nCi} / \mathrm{g}$.

Precipitate formation was addressed by adding different volumes of the $0.05 \underline{\mathrm{M}}$ $\mathrm{H}_{2} \mathrm{C}_{2} \mathrm{O}_{4}$ in $3 \mathrm{M} \mathrm{HNO}_{3}$ scrub solution to constant volumes of Run 74 calcine spiked with Am-


to simulate a range of feed to scrub flowrates. This test was performed by adding $9 \mathrm{mLs}$ of Run 74 to four test tubes. Am-241 was spiked into each test tube by adding $0.05 \mathrm{~mL}$ of the Am-241 standard having an activity of $1.65 \mathrm{E}+5 \mathrm{dps} / \mathrm{mL}$. Each test tube was mixed for 1 
minute on a vortex mixer and a $1 \mathrm{~mL}$ sample was taken to ascertain the initial Am-241

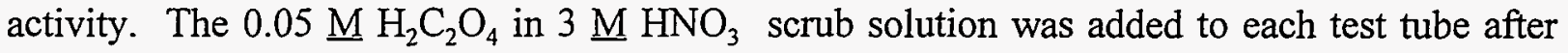
sampling to provide the above stated ratios. The solutions were again mixed for 1 minute on a vortex mixer and allowed to stand for 1 hour. Samples were taken from each test tube after 1 hour and analyzed for Am-241 activity to determine if any activity was lost. No visible precipitates were observed in any of the test tubes; therefore the solutions were not centrifuged or filtered prior to sampling. Results from this test are shown in Table 7.

Table 7: Feed Stability Test for $0.05 \underline{\mathrm{M}} \mathrm{H}_{2} \mathrm{C}_{2} \mathrm{O}_{4}$ in $3 \underline{\mathrm{M}} \mathrm{HNO}_{3}$ Scrubs

\begin{tabular}{|c|c|c|c|c||}
\hline $\begin{array}{c}\text { Feed:Scrub } \\
\text { Ratio }\end{array}$ & $\begin{array}{c}\text { Initial Am-241 } \\
\text { Activity } \\
\text { (dps/mL) }\end{array}$ & $\begin{array}{c}\text { Am-241 } \\
\text { Activity After } \\
\text { Scrub Dilution } \\
\text { (dps/mL) }\end{array}$ & $\begin{array}{c}\text { Final Am-241 } \\
\text { Activity } \\
\text { (dps/mL) }\end{array}$ & $\begin{array}{c}\text { Material } \\
\text { Balance } \dagger\end{array}$ \\
\hline $8: 1$ & 57,800 & 51,378 & 51,627 & $99.5 \%$ \\
\hline $8: 2$ & 58,183 & 46,546 & 45,950 & $100 \%$ \\
\hline $8: 3$ & 58,483 & 42,533 & 41,736 & $102 \%$ \\
\hline $8: 4$ & 58,432 & 38,955 & 38,160 & $102 \%$ \\
\hline
\end{tabular}

$\dagger$ (Am-241 activity after scrub dilution/final Am-241 activity) x 100

Data shown in Table 7 show that no Am-241 activity was lost in any of the feed scrub mixtures after 1 hour, which would indicate the feed and scrub mixture to be stable with regards to precipitation. Even though the test duration of 1 hour is well beyond the expected residence time of the feed/scrub mixture in the extraction section of a counter current sytsem, this test should be repeated by allowing the spiked feed and scrub mixture to set for an extended period of time to ensure that precipitate formations are not kinetically slow.

The $0.05 \mathrm{M} \mathrm{H}_{2} \mathrm{C}_{2} \mathrm{O}_{4}$ in $3.0 \underline{\mathrm{M}} \mathrm{HNO}_{3}$ scrubbed solvents used to obtain data in Tables 4 and 6 were contacted with either $0.04 \mathrm{M}$ HEDPA in $0.04 \mathrm{M} \mathrm{HNO}_{3}$ or $0.05 \mathrm{M} \mathrm{H}_{2} \mathrm{C}_{2} \mathrm{O}_{4}$ in 0.01 $\underline{\mathrm{M}} \mathrm{HNO}_{3}$ to evaluate the stripping behavior of the actinides and technetium from the $0.75 \underline{\mathrm{M}}$ CMP solvent. Selective stripping of the actinides from the solvent is not desirable; therefore, stripping reagents capable of a gross actinide recovery were evaluated. Stripping distribution 
coefficients for the actinides and technetium using these two stripping reagents are shown in Tables 8 and 9.

Table 8: Stripping Distribution Coefficients Using $0.04 \underline{\mathrm{M}} \mathrm{HEDPA}$ in $0.04 \underline{\mathrm{M}} \mathrm{HNO}_{3}$

\begin{tabular}{|c|c|c|c|c|c||}
\hline \hline Contact & $\mathrm{D}_{\mathrm{U}}$ & $\mathrm{D}_{\mathrm{Pu}}$ & $\mathrm{D}_{\mathrm{Np}}$ & $\mathrm{D}_{\mathrm{Am}}$ & $\mathrm{D}_{\mathrm{Tc}}$ \\
\hline $\mathrm{St} 1$ & 0.04 & 0.06 & 0.047 & 0.32 & 20 \\
\hline $\mathrm{St} 2$ & 0.004 & 0.01 & 0.155 & 0.01 & 40 \\
\hline $\mathrm{St} 3$ & $<<1$ & 0.035 & No Data & $<<1$ & 59 \\
\hline
\end{tabular}

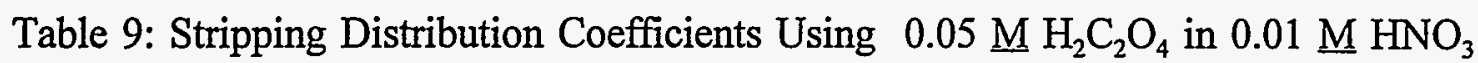

\begin{tabular}{||c|c|c|c|c||}
\hline \hline Contact & $\mathrm{D}_{\mathrm{U}}$ & $\mathrm{D}_{\mathrm{Pu}}$ & $\mathrm{D}_{\mathrm{Np}}$ & $\mathrm{D}^{1}{ }_{\mathrm{Am}}$ \\
\hline St1 & 12.73 & 0.93 & 0.43 & 0.50 \\
\hline St2 & 1.39 & 0.49 & 0.25 & 0.03 \\
\hline St3 & 0.46 & 0.19 & $<0.25$ & $<<1$ \\
\hline
\end{tabular}

1. Am-241 stripping distribution coefficients obtained with $0.1 \mathrm{M} \mathrm{H}_{2} \mathrm{C}_{2} \mathrm{O}_{4}$ in $0.01 \mathrm{M}$ $\mathrm{HNO}_{3}$

The data shown in Tables 8 and 9 indicate that dilute HEDPA is much more efficient at stripping the actinides, especially uranium, than dilute oxalic acid; however, HEDPA did not strip Tc. No data is available regarding $\mathrm{H}_{2} \mathrm{C}_{2} \mathrm{O}_{4}$ ability to strip Tc. Based on data from this test, HEDPA in dilute nitric acid was chosen as the stripping reagent of choice.

\subsection{CMP Tests}

During the development of the CMP flowsheet, an evaluation of the dispersion numbers indicated that the $0.75 \mathrm{M}$ CMP solvent may cause flooding problems when tested in the centrifugal contactor design currently available at the ICPP $[19,20]$. Dispersion numbers 
are unitless values that provide an indication of how well the solvent and aqueous phases separate from one another. The larger the dispersion number the more difficult one phase separates from the other, which indicates that flooding may occur in the contactor. The dispersion numbers were evaluated to determine which solvent composition would have the best hydraulic properties for use in the $5.5 \mathrm{~cm}$ contactor design being used at the ICPP. Contactor design can be tailored around the hydraulic properties of a given solvent. The ICPP $5.5 \mathrm{~cm}$ contactor design was based on the TRUEX solvent $(0.2 \underline{\mathrm{M}}$ CMPO and $1.4 \underline{\mathrm{M}}$ TBP in an NPH diluent) and not the CMP solvent. Rather than purchasing new contactors capable of efficient use with the $0.75 \underline{\mathrm{M}} \mathrm{CMP}$ solvent, adjustments were made to the CMP solvent that would allow for testing in the current contactor system. The primary adjustment in the solvent was varying the CMP concentration until the hydraulic properties of the solvent were conducive to the $5.5 \mathrm{~cm}$ contactors.

Solvent composition was also adjusted around the extraction $\mathrm{D}_{\mathrm{Zr}}$ and $\mathrm{D}_{\mathrm{Am}}$ values. $\mathrm{A}$ solvent having desirable hydraulic properties but inefficient at extracting americium would be unacceptable. Two solvents, 0.5 and $0.25 \underline{\mathrm{M}} \mathrm{CMP}$, both in $1.0 \underline{\mathrm{M}} \mathrm{TBP}$, were shown to have acceptable dispersion numbers with the feed, scrub, strip, and wash solutions and were chosen for further testing. Extraction $\mathrm{D}_{\mathrm{Zr}}$ and $\mathrm{D}_{\mathrm{Am}}$ were determined for these two solvents from spiked Run 74 feeds by contacting each solvent three times with equal volumes of the fresh


$3 \underline{\mathrm{M} \mathrm{HNO}} \mathrm{H}_{3}$. Extraction and scrub data from this test are shown in Table 10. The $0.75 \underline{\mathrm{M}}$ CMP data are also shown for comparison.

Little difference in $\mathrm{D}_{\mathrm{Zr}}$ was observed between the $0.75 \underline{\mathrm{M}}$ and $0.5 \underline{\mathrm{M}} \mathrm{CMP}$ solvents. The $0.25 \underline{\mathrm{M}}$ CMP solvent extracted approximately $66 \%$ less zirconium than either the $0.75 \underline{\mathrm{M}}$ or $0.5 \underline{\mathrm{M}} \mathrm{CMP}$ solvents. Even though this is a desirable attribute of the $0.25 \underline{\mathrm{M}} \mathrm{CMP}$ solvent, the extraction and scrub $D_{A m}$ may be to small for efficient Am removal. Almost $50 \%$ of the americium is lost in the scrub contacts and the relatively small extraction $\mathrm{D}_{\mathrm{Am}} \sim 2.5$ indicates relatively poor americium removal. Since $>99 \%$ of the americium must be removed from the dissolved calcine feeds, it is doubtful that the extraction and scrub $\mathrm{D}_{\mathrm{Am}}$ for the $0.25 \underline{\mathrm{M}} \mathrm{CMP}$ solvent would result in an aqueous raffinate waste capable of consistantly meeting the Class 
A waste limit criteria. The $0.5 \mathrm{M}$ CMP solvent does exhibit extraction and scrub $\mathrm{D}_{\mathrm{Am}}$ suitable for americium removal from the dissolved calcine feed and was chosen as an acceptable solvent for further testing.

Table 10: Zirconium and Americium Extraction Distribution Coefficients as a Function of CMP Concentration

\begin{tabular}{||c|c|c|c|c|c|c||}
\hline & \multicolumn{2}{|c|}{$0.75 \underline{\mathrm{M}} \mathrm{CMP}$} & \multicolumn{2}{c|}{$0.5 \underline{\mathrm{M}} \mathrm{CMP}$} & \multicolumn{2}{c|}{$0.25 \underline{\mathrm{M}} \mathrm{CMP}$} \\
\hline Contact & $\mathrm{D}_{\mathrm{zr}}$ & $\mathrm{D}_{\mathrm{Am}}$ & $\mathrm{D}_{\mathrm{zr}}$ & $\mathrm{D}_{\mathrm{Am}}$ & $\mathrm{D}_{\mathrm{zr}}$ & $\mathrm{D}_{\mathrm{Am}}$ \\
\hline $\mathrm{E} 1$ & 0.22 & 14.3 & 0.18 & 8.6 & 0.08 & 2.3 \\
\hline $\mathrm{E} 2$ & 0.24 & 14.6 & 0.19 & 8.5 & 0.09 & 2.5 \\
\hline $\mathrm{E} 3$ & 0.25 & 14.3 & 0.19 & 8.3 & 0.1 & 2.6 \\
\hline $\mathrm{Sc} 1$ & 0.054 & 7.05 & 0.05 & 3.4 & $<0.1$ & 1.0 \\
\hline $\mathrm{Sc} 2$ & $<<1$ & 7.39 & $<0.6$ & 3.8 & $\mathrm{NA}$ & 1.1 \\
\hline $\mathrm{Sc} 3$ & $\mathrm{NA}$ & 7.41 & $\mathrm{NA}$ & 3.7 & $\mathrm{NA}$ & 1.1 \\
\hline
\end{tabular}

$\mathrm{NA}=$ no activity in either phase

Figures 2 and 3 are distribution coefficient profiles for the extraction of americium and zirconium into the $0.5 \mathrm{M} \mathrm{CMP}$ solvent as a function of equilibrium aqueous phase $\mathrm{HNO}_{3}$ concentration. Favorable americium extraction $\mathrm{D}^{\prime}$ s are observed when the $\left[\mathrm{HNO}_{3}\right]>2 \mathrm{M}$ $\mathrm{HNO}_{3}$, where $\mathrm{D}_{\mathrm{Am}}$ are $>2$. Americium can be stripped from the $0.5 \underline{\mathrm{M}} \mathrm{CMP}$ solvent using solutions $<1 \mathrm{M} \mathrm{HNO}_{3}$, but favorable americium stripping D's occur when the $\left[\mathrm{HNO}_{3}\right]<0.1$ $\mathrm{M} \mathrm{HNO}_{3}$. Zirconium significantly extracts from pure nitric acid solutions when $\left[\mathrm{HNO}_{3}\right]>0.5$ $\underline{\mathrm{M}} \mathrm{HNO}_{3}$ where $\mathrm{D}_{\mathrm{zr}}$ are $>1$. Extrapolating the zirconium distribution profile from the curve shown in Figure 5 also indicates that removing zirconium from the $0.5 \underline{\mathrm{M}} \mathrm{CMP}$ solvent will be difficult using very dilute nitric acid solutions. 


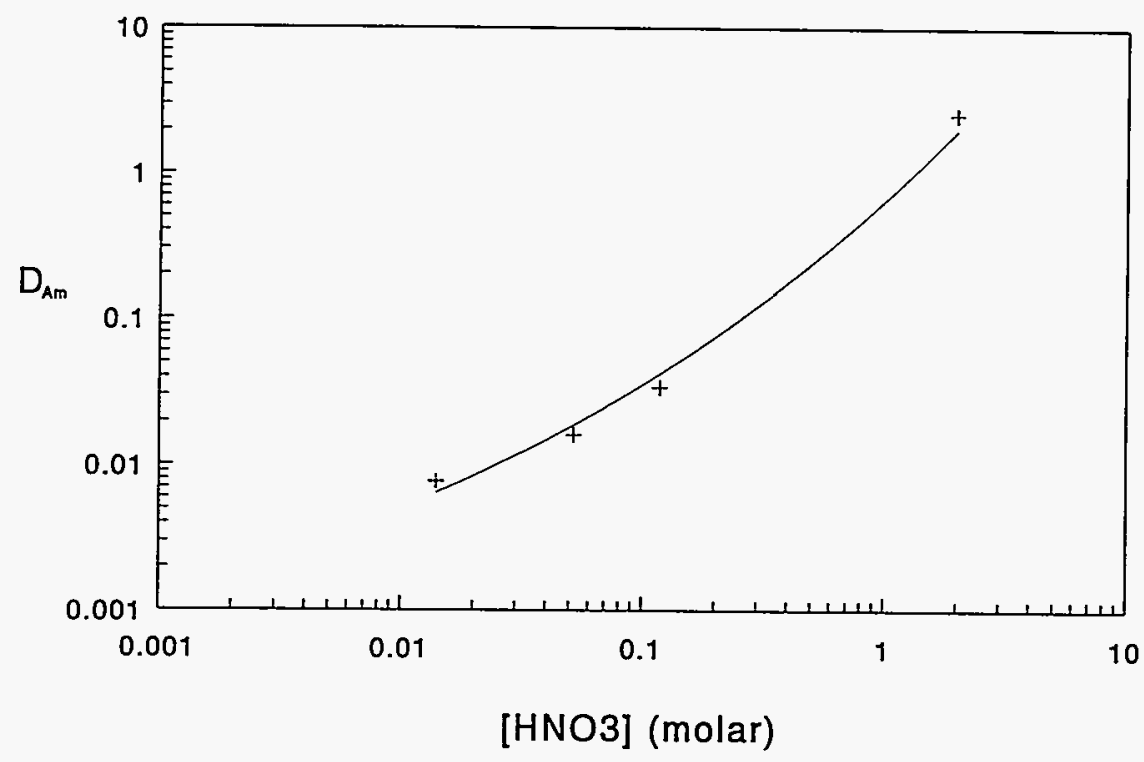

Figure 2: $\mathrm{D}_{\mathrm{Am}}$ as a function of $\left[\mathrm{HNO}_{3}\right]$ using $0.5 \underline{\mathrm{M}} \mathrm{CMP}$ and $1.0 \underline{\mathrm{M}}$ TBP in Isopar $\mathrm{L}^{\otimes}$

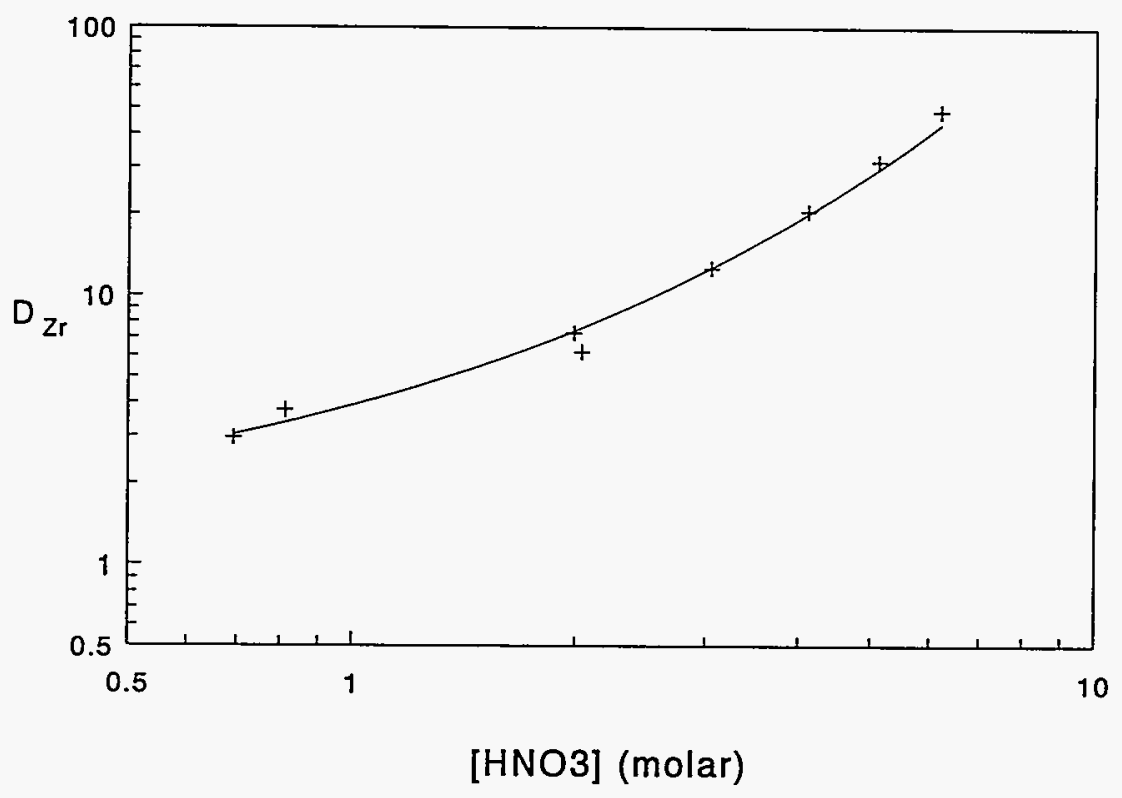

Figure 3: $\mathrm{D}_{\mathrm{Zr}}$ as a function of $\left[\mathrm{HNO}_{3}\right]$ using $0.5 \underline{\mathrm{M}} \mathrm{CMP}$ and $1.0 \underline{\mathrm{M}}$ TBP in Isopar $\mathrm{L}^{\circledR}$ 
$D_{A m}$ and $D_{z r}$ data shown in Figures 2 and 3 suggest that selectively scrubbing zirconium from $0.5 \mathrm{M} \mathrm{CMP}$ using nitric acid is impossible to perform without causing significant americium stripping. Baker, et al., used $3 \underline{\mathrm{M}} \mathrm{HNO}_{3}$ to scrub extracted zirconium during a counter-current test performed with a $\mathrm{Zr}-\mathrm{Al}$ first cycle raffinate and 20 vol.\% $\mathrm{CMP}$ (dihexyl analogue) in decalin and DIPB [10]. Even though Baker does not report a $\mathrm{D}_{\mathrm{zr}}$ for the $3 \underline{\mathrm{M} \mathrm{HNO}} \mathrm{HN}_{3}$ scrub, McIsaac [21] reports a $\mathrm{D}_{\mathrm{zr}}=0.016$ when also using $3 \underline{\mathrm{M}} \mathrm{HNO}_{3}$ to scrub $\mathrm{Zr}$ that extracted from a feed and into a solvent having compositions analogous to those used by Baker [10]. Schulz [22] also reports a scrub $\mathrm{D}_{\mathrm{zr}}=0.066$ when $6.0 \mathrm{M} \mathrm{HNO}_{3}$ is contacted with 30 vol\% CMP (dihexyl analogue) in xylene (the zirconium was loaded into the solvent from $\mathrm{Zr}$-Al first cycle simulant). The zirconium scrub D's reported by McIsaac [21] and Schulz [22] seem to countradict the $\mathrm{D}_{\mathrm{Zr}}$ data shown in Figure 3. This countradiction is explained by the difference in solvent compositions used by McIsaac, Schulz, and the present work. Therefore, a comparison of zirconium D's between previous work and those reported here is invalid because of the drastic differences in the solvents used.

The zirconium data shown in Figure 3 would also appear to contradict the data observed when contacting the dissolved calcine feed with the CMP solvent, where very small

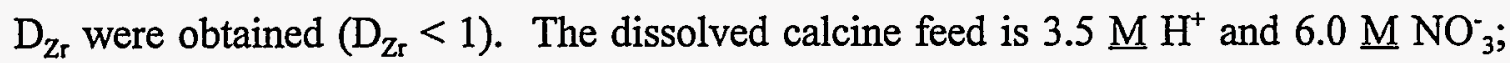
therefore, the $\mathrm{D}_{\mathrm{zr}}$ would be expected to be $>10$ (Figure 3). However, the majority of the zirconium in the dissolved calcine is complexed by fluoride ( $0.9 \mathrm{M})$ which inhibits zirconium extraction. Zirconium scrubbing data shown in Table 4, where $1.5 \underline{\mathrm{M}} \mathrm{HNO}_{3}$ and $0.75 \underline{\mathrm{M}}$ CMP were used, again seem to contradict the zirconium data shown in Figure 3. $\mathrm{D}_{\mathrm{zr}}<1$ were obtained for the first two scrub contacts using $1.5 \mathrm{M} \mathrm{HNO}_{3}$ and a larger CMP concentration. $\mathrm{A} \mathrm{D}_{\mathrm{zr}}=1.2$ was obtained in the final $\mathrm{Sc} 3$ scrub contact. Figure 3 shows a $\mathrm{D}_{\mathrm{zr}}$ $\sim 3.5$ for $1.5 \mathrm{M} \mathrm{HNO}_{3}$. This discrepancy may be due to a difference in the species of extracted zirconium.

Uranium and plutonium were spiked into Run 74 dissolved calcine in order to conduct tests to determine extraction, scrub, strip, and wash distribution coefficients for these two elements using $0.5 \mathrm{M}$ CMP. The scrub and strip solutions used for this test were $0.05 \mathrm{M}$ $\mathrm{H}_{2} \mathrm{C}_{2} \mathrm{O}_{4}$ in $3 \underline{\mathrm{M}} \mathrm{HNO}_{3}$ and $0.04 \underline{\mathrm{M}} \mathrm{HEDPA}$ in $0.04 \underline{\mathrm{M} \mathrm{HNO}} \mathrm{H}_{3}$, respectively. A $0.25 \underline{\mathrm{M}}$ 
performed with fresh aqueous phases being used for each contact. The data from this test are shown in Table 11.

A comparison of the uranium and plutonium distribution coefficients shown in Table 11 with those shown in Tables 3, 6, and 8 shows very little change in the extraction, scrub, and strip distribution coefficients for uranium and plutonium between the $0.75 \underline{\mathrm{M}}$ and $0.5 \underline{\mathrm{M}}$ CMP solvents.

The excellent hydraulic properties offered by the $0.5 \mathrm{M}$ CMP solvent, and the distribution coefficient data shown in Tables 10 and 11 suggest this solvent composition as the primary candidate for further testing.

Table 11: Uranium and Plutonium Distribution Coefficients Using 0.5 M CMP

\begin{tabular}{||c|c|c||}
\hline \hline Contact & $\mathrm{D}_{\mathrm{U}}$ & $\mathrm{D}_{\mathrm{Pu}}$ \\
\hline $\mathrm{E} 1$ & 210 & 71.4 \\
\hline $\mathrm{E} 2$ & 220 & 71.8 \\
\hline $\mathrm{E} 3$ & 224 & 71.7 \\
\hline $\mathrm{Sc} 1$ & 78.8 & 21.1 \\
\hline $\mathrm{Sc} 2$ & 67.6 & 15.6 \\
\hline Sc3 & 65.3 & 14.4 \\
\hline $\mathrm{St} 1$ & 0.016 & 0.027 \\
\hline $\mathrm{St} 2$ & 0.002 & 0.008 \\
\hline $\mathrm{St3}$ & $\mathrm{NA}$ & $<0.3$ \\
\hline $\mathrm{W} 1$ & $\mathrm{NA}$ & $<0.1$ \\
\hline $\mathrm{W} 2$ & $\mathrm{NA}$ & $<0.3$ \\
\hline
\end{tabular}

$\overline{\mathrm{NA}}=$ No activity detected in either phase 


\section{Feed Adjustments}

Feed adjustments were evaluated during the development of actinide separations processes for dissolved zirconium calcine feeds. These feeds contain significant quantities of chromium and zirconium, both of which can extract and be recovered with the actinides. The extraction of these two elements have caused physical problems associated with the solvent and consume precious extractant to the point of suppressing actinide extraction. The recovery of these elements with the actinides may cause an increase in the HLW glass or glass-ceramic final waste volume, which is also undesirable. Even though scrubbing zirconium with $0.05 \mathrm{M}$ $\mathrm{H}_{2} \mathrm{C}_{2} \mathrm{O}_{4}$ in $3 \mathrm{M} \mathrm{HNO}_{3}$ suggests a plausable means of preventing its recovery with the actinides, a brief discussion of work performed to prevent its extraction is provided.

\section{Chromium Extraction}

Chromium has been known to extract into solvents containing TBP [23] as chromate at $\mathrm{pH}<6$. Most ICPP calcines will contain $\mathrm{Cr}$ which is most likely present as chromate $\left(\mathrm{CrO}_{4}^{-2}\right)$ because of the oxidizing environment in the calcination process. Run 74 calcine contained $0.4 \mathrm{wt} \% \mathrm{Cr}$ prior to dissolution and $5.3 \times 10^{-3} \mathrm{M} \mathrm{Cr}$ following dissolution. Chromium is most likely present as dichromate, $\mathrm{Cr}_{2} \mathrm{O}_{7}^{-2}$, in the acidic dissolved calcine. Physical problems, such as third phase formation during extraction contacts and interfacial crud formation during solvent wash contacts, were observed in early work performed with the TRUEX solvent (0.2 $\underline{\mathrm{M}}$ CMPO, $1.4 \underline{\mathrm{M}}$ TBP in dodecane) and Run 74 dissolved calcine [11]. These problems were eliminated by reducing the calcine with either ascorbic acid, hydrogen peroxide, or ferrous sulfamate. Reducing the feed with any of these reductants caused the feed to

change from the yellow dichromate color to the blue $\mathrm{Cr}(\mathrm{III})$ color, and also eliminated the third phase and interfacial crud problems. These data indicate that chromate extraction was the culprit causing the physical problems with the TRUEX solvent. 
The success achieved by reducing the feed in the TRUEX process was applied to CMP process in order to inhibit dichromate extraction. Even though the CMP solvent contains 1.0 $\underline{\mathrm{M}} \mathrm{TBP}$, as opposed to the $1.4 \underline{\mathrm{M}} \mathrm{TBP}$ in the TRUEX solvent, the CMP solvent still extracted significant amounts of dichromate. Tests performed with reduced Run 74 dissolved calcine resulted in a "cleaner" solvent (the solvent remained opaque as opposed to dark yellow) throughout the extraction, scrub, strip, and wash contacts. Chromium distribution coefficients using reduced and non-reduced feeds with $0.5 \mathrm{M}$ CMP solvent are shown in Table 12 .

Table 12: $\mathrm{D}_{\mathrm{Cr}}$ for Extraction, Scrub, Strip, and Wash Contacts

\begin{tabular}{||c|c|c||}
\hline Contact & $\mathrm{D}_{\mathrm{Cr}}$ Reduced Feed & $\mathrm{D}_{\mathrm{Cr}}$ Non-Reduced Feed \\
\hline $\mathrm{E} 1$ & 0.037 & 0.36 \\
\hline $\mathrm{E} 2$ & 0.066 & 0.49 \\
\hline $\mathrm{E} 3$ & 0.062 & 0.54 \\
\hline $\mathrm{Sc} 1$ & 0.082 & 1.34 \\
\hline $\mathrm{Sc} 2$ & 0.76 & 1.67 \\
\hline $\mathrm{Sc} 3$ & 0.75 & 7.84 \\
\hline $\mathrm{St} 1$ & 2.55 & 5.31 \\
\hline $\mathrm{St} 2$ & 0.70 & 8.41 \\
\hline $\mathrm{St} 3$ & $\begin{array}{c}\text { Aqueous value below } \\
\text { detection limit }\end{array}$ & 7.09 \\
\hline $\mathrm{W} 1$ & $\begin{array}{c}{ }^{1} \\
\text { Aqueous value below } \\
\text { detection limit }^{1}\end{array}$ & 0.044 \\
\hline $\mathrm{W} 2$ & $\begin{array}{c}\text { Aqueous value below } \\
\text { detection limit }^{1}\end{array}$ & 0.0075 \\
\hline
\end{tabular}

1. Analytical detection limit $=0.03 \mathrm{ppm}$

Chromium distribution coefficients shown in Table 12 were determined by assuming a material balance of $100 \%$ and calculating the organic phase $\mathrm{Cr}$ 
concentration by difference $\left(\mathrm{Cr}_{\mathrm{Org}}=\mathrm{Cr}_{\mathrm{Aq}}\right.$ in $\left.-\mathrm{Cr}_{\mathrm{Aq} \text { ou }}\right)$. Only the aqueous phases were sampled and analyzed for $\mathrm{Cr}$. Using the material balance to calculate the organic phase $\mathrm{Cr}$ concentration causes greater uncertainty in $\mathrm{D}_{\mathrm{Cr}}$, especially in those samples with very little $\mathrm{Cr}$, because the analytical error is compounded with each successive contact. However, these errors should be inconsequential when comparing $\mathrm{D}_{\mathrm{Cr}}$ for a specific contact associated with the reduced and non-reduced feeds.

Chromium extraction distribution coefficients into the CMP solvent from the non-reduced feed are approximately an order of magnitude larger than the extraction distribution coefficients observed in the reduced feed. The difference in $\mathrm{D}_{\mathrm{Cr}}$ between the two feeds is assumed to be the difference between $\mathrm{Cr}(\mathrm{VI})$ and $\mathrm{Cr}(\mathrm{III})$ extraction. The $\mathrm{Cr}$ extraction distributions are consistant with those observed by Schulz and McIsaac [24], where $\mathrm{Cr}_{2} \mathrm{O}_{7}^{-}$is reported to extract considerably more strongly than $\mathrm{Cr}^{+3}$ into CMP solutions.

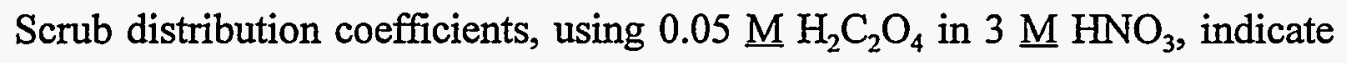
that dilute oxalic acid is ineffective in scrubbing $\mathrm{Cr}(\mathrm{VI})$ from the CMP solvent. Chromium scrub D's are smaller for those contacts with the CMP solvent previously contacted with the reduced feed. This may indicate that $\mathrm{Cr}(\mathrm{III})$ is scrubbed from the solvent using the dilute oxalic acid/high nitric acid scrub solution.

Stripping $\mathrm{Cr}(\mathrm{VI})$ from the solvent contacted with the non-reduced feed shows $0.04 \underline{\mathrm{M}}$ HEDPA to be ineffective in removing $\mathrm{Cr}(\mathrm{VI})$. Even though a $\mathrm{D}_{\mathrm{Cr}}<1$ was obtained in the first strip contact in the reduced feed test, the $\mathrm{Cr}$ concentration analytically determined in the first strip solution was near the analytical detection limit. This may indicate that HEDPA is more effective at stripping $\mathrm{Cr}(\mathrm{III})$, as opposed to $\mathrm{Cr}(\mathrm{VI})$, provided the St1 value is assumed realistic. Strip $\mathrm{D}_{\mathrm{Cr}}$ from the test using non-reduced feed are $>1$ and are much more reliable because of the higher $\mathrm{Cr}$ concentrations found in these samples.

Sodium carbonate $(0.25 \underline{\mathrm{M}})$ does seem to efficiently remove $\mathrm{Cr}$ from the solvent. Contacts with the non-reduced feed show the wash $\mathrm{D}_{\mathrm{Cr}}<<1$. Chromium concentrations were below the analytical detection limit of $0.03 \mathrm{ppm}$ in the wash 
samples from the reduced feed test.

Even though the $\mathrm{Cr}(\mathrm{VI})$ extraction distribution coefficient is small $\left(\mathrm{D}_{\mathrm{Cr}}<1\right)$, chromium reduction is recommended for dissolved calcine feeds prior to contact with the CMP solvent. This recommendation is based on the $\mathrm{Cr}$ problems observed in the TRUEX testing [11], where small amounts of chromium in the solvent caused physical problems during extraction and wash contacts.

\section{Zirconium Extraction}

Inhibiting zirconium extraction from dissolved zirconium calcines, such as Run 74 , by adjusting the feed with zirconium complexing reagents was also investigated. Zirconium extraction into the CMP solvent is $<1$, but the large zirconium concentration in the feed may cause a significant zirconium mass in the solvent.

Several zirconium complexing reagents were evaluated during the TRUEX flowsheet development [11]. Fluoride, ammonium oxalate, ketomalonic acid, tetrahydrofurran carboxylic acid, and HEDPA were all evaluated as potential zirconium masking reagents. Most of these complexing agents caused precipitations to occur in the feed. Fluoride, HEDPA, and oxalate compounds caused severe precipitations (mostly calcium salts) in the feed even when small amounts were added. Those reagents that were stable in the feed did not reduce the $\mathrm{D}_{\mathrm{Zr}}$ extraction into the TRUEX solvent. The lack of success in preventing zirconium extraction precluded the use of complexing reagents during CMP flowsheet development. Even though CMP is not as strong of an extractant as CMPO, other means of preventing zirconium from following the actinides into the HLW stream, such as selective scrubbing, were pursued.

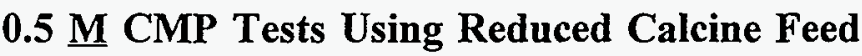

Actinide, zirconium, and technetium extraction distribution coefficients were evaluated 
from Run 74 feed reduced with $30 \% \mathrm{H}_{2} \mathrm{O}_{2}$. The loaded solvent was scrubbed with $0.05 \underline{\mathrm{M}}$ $\mathrm{H}_{2} \mathrm{C}_{2} \mathrm{O}_{4}$ in $3.0 \mathrm{M} \mathrm{HNO}_{3}$ to remove zirconium. The scrubbed solvent was then stripped with $0.001 \mathrm{M}$ HEDPA. The purposes of these tests were to determine if feed reduction adversely affected the extraction of these key elements and to optimize the HEDPA strip concentration. Optimization of the HEDPA strip solution is important to reduce the amount of phosphate reporting to the HAW fraction. Phosphate, like zirconium, may adversely increase the final HAW glass or glass-ceramic waste volume.

\section{Extraction From Reduced Run 74 Feed}

Run 74 calcine was spiked with either Pu-238, U-233, Np-239, Tc-99, Zr-95, or Am-241. The spiked feeds were allowed to equilibrate for at least 24 hours before reduction with $30 \% \mathrm{H}_{2} \mathrm{O}_{2}$. Each feed was then reduced with $20 \mu \mathrm{L}$ of $30 \% \mathrm{H}_{2} \mathrm{O}_{2}$ and allowed to equilibrate for an additional 24 hours prior to contact with $0.5 \underline{\mathrm{M}} \mathrm{CMP}$. Three equal volume extraction contacts were performed with fresh reduced feed being used for each contact. Extraction distribution coefficients from these tests are shown in Table 13.

Table 13: $\mathrm{Zr}, \mathrm{Tc}$, and Actinide Extraction into $0.5 \underline{\mathrm{M}} \mathrm{CMP}$ from Reduced Run 74 Feeds

\begin{tabular}{|c|c|c|c|c|c|c||}
\hline \hline Contact & $\mathrm{D}_{\mathrm{Zr}}$ & $\mathrm{D}_{\mathrm{Am}}$ & $\mathrm{D}_{\mathrm{Pu}}$ & $\mathrm{D}_{\mathrm{U}}$ & $\mathrm{D}_{\mathrm{Np}}$ & $\mathrm{D}_{\mathrm{Tc}}$ \\
\hline $\mathrm{E} 1$ & 0.19 & 7.4 & 73.5 & 143 & $>55$ & 0.72 \\
\hline $\mathrm{E} 2$ & 0.22 & 7.0 & 78.5 & 195 & $>100$ & 0.73 \\
\hline $\mathrm{E} 3$ & 0.22 & 7.1 & 78.5 & 195 & 58.3 & 0.72 \\
\hline
\end{tabular}

A comparison of the $\mathrm{Zr}, \mathrm{Am}, \mathrm{Pu}$, and $\mathrm{U}$ distribution coefficients shown in Tables 10 and 11 to those shown in Table 13 indicate little change in the extraction of these elements between non-reduced and reduced feeds. Tetravalent plutonium is reduced to trivalent plutonium by hydrogen peroxide in highly acidic solutions [25]. 
Tests conducted with plutonium spiked simulant before reduction have shown that the plutonium is partitioned between $\mathrm{Pu}(\mathrm{IV})$ and $\mathrm{Pu}(\mathrm{VI}) ; 30 \%$ of the plutonium being $\mathrm{Pu}(\mathrm{IV})$ and $70 \%$ being $\mathrm{Pu}(\mathrm{VI})$. Hydrogen peroxide could also reduce $\mathrm{Pu}(\mathrm{VI})$ all the way to $\mathrm{Pu}(\mathrm{III})$ [17]. Even though the $\mathrm{D}_{\mathrm{Pu}}$ indicate that plutonium was not extensively reduced to $\mathrm{Pu}(\mathrm{III})\left(\mathrm{D}_{\mathrm{Pu}(\mathrm{III})}<\mathrm{D}_{\mathrm{Pu}(\mathrm{VI})}<\mathrm{D}_{\mathrm{Pu}(\mathrm{IV})}\right)$, the likelihood of this is doubtful. Any reduced plutonium could have been re-oxidized by the dissolved calcine solution since no holding reductant was present. The redox chemistry of plutonium is complex in even simple solutions, the complicated matrix of the dissolved zirconium calcine adds to this complexity.

A comparison of the neptunium extraction data shown in Table 3 to those shown in Table 13 does indicate that neptunium may have been reduced. The $D_{\mathrm{Np}}$ in Table 3 were obtained with $0.75 \underline{\mathrm{M}} \mathrm{CMP}$ rather than $0.5 \underline{\mathrm{M}} \mathrm{CMP}$ which may make this comparison dubious. Comparing the extraction D's of the other elements listed in Tables 3 and 13 does not indicate such a drastic difference. $D_{\text {Am }}$ did decrease from 15 in the $0.75 \underline{\mathrm{M}} \mathrm{CMP}$ solvent to 7 in the $0.5 \underline{\mathrm{M}} \mathrm{CMP}$ solvent, but $\mathrm{D}_{\mathrm{Np}}$ went from 350 (E3) to 58 (E3). This 7 fold decrease in $\mathrm{D}_{\mathrm{Np}}$ is expected to be from a combination of reduced CMP concentration and hydrogen peroxide reduction.

As previously mentioned, the large $D_{\mathrm{Np}}$ observed in tests using $0.75 \underline{\mathrm{M}} \mathrm{CMP}$ were attributed to the disproportionation of $\mathrm{Np}(\mathrm{V})$ to $\mathrm{Np}(\mathrm{IV})$ and $\mathrm{Np}(\mathrm{VI})$. This conclusion is supported by $\mathrm{Np}(\mathrm{IV})$ and $\mathrm{Np}$ (VI) distribution coefficients into $30 \% \mathrm{CMP}$ reported by Maxey [15]. The disproportionation of $\mathrm{Np}(\mathrm{V})$, shown in Equation 3, is not large [17] but is very dependant on the acid concentration.

$$
2 \mathrm{NpO}_{2}^{+}+4 \mathrm{H}^{+}=\mathrm{Np}+4+\mathrm{NpO}_{2}^{+2}+2 \mathrm{H}_{2} \mathrm{O} \quad K_{e q}=10^{-7}
$$

The acid concentration in the dissolved calcine may be large enough to cause this disproportionation; however, the significant dichromate concentration prior to reduction may also contribute to $\mathrm{Np}(\mathrm{V})$ disproportionation. TBP does contribute to neptunium extraction but neptunium extraction into TBP is negligible compared to 
CMP [17]. Katz [17] reports that the reduction of $\mathrm{Np}(\mathrm{VI})$ to $\mathrm{Np}(\mathrm{V})$ by $\mathrm{H}_{2} \mathrm{O}_{2}$ occurs very rapidly in nitric acid solutions, while the reduction of $\mathrm{Np}(\mathrm{V})$ to $\mathrm{Np}(\mathrm{IV})$ by $\mathrm{H}_{2} \mathrm{O}_{2}$ occurs very slowly in nitric acid. The re-oxidation of $\mathrm{Np}(\mathrm{IV})$ to $\mathrm{Np}(\mathrm{V})$ by $\mathrm{NO}_{3}^{-}$also occurs very slowly. If equilibrium conditions are assumed, i.e., that the 24 hour equilibration period after feed reduction was enough time for any $\mathrm{Np}(\mathrm{V})$ to be reduced by $\mathrm{H}_{2} \mathrm{O}_{2}$ to $\mathrm{Np}(\mathrm{IV})$ and for $\mathrm{Np}(\mathrm{IV})$ to be re-oxidized to $\mathrm{Np}(\mathrm{V})$, then the decrease in $D_{\mathrm{Np}}$ can be attributed to the reduction of $\mathrm{Np}(\mathrm{VI})$ to $\mathrm{Np}(\mathrm{V})$ and the re-oxidation of $\mathrm{Np}(\mathrm{IV})$ to $\mathrm{Np}(\mathrm{V})$.

\section{HEDPA Strip Concentration}

The loaded solvent(s) from tests described above were scrubbed with $0.05 \underline{\mathrm{M}}$ $\mathrm{H}_{2} \mathrm{C}_{2} \mathrm{O}_{4}$ in $3.0 \underline{\mathrm{M} \mathrm{HNO}} \mathrm{HN}_{3}$ to remove extracted zirconium prior to performing HEDPA strip contacts. Three equal volume scrub contacts were performed with fresh scrub solution used in each contact. Scrub distribution coefficients are shown in Table 14. Scrub distribution coeffients shown in Table 14 are smaller than those obtained using 0.75 M CMP. Smaller scrub D's are expected with the less concentrated CMP solvent.

Table 14: Scrub Distribution Coefficients from $0.5 \mathrm{M}$ CMP Using $0.05 \underline{\mathrm{M} \mathrm{H}} \mathrm{H}_{2} \mathrm{O}_{4}$ in $3.0 \underline{\mathrm{M}} \mathrm{HNO}_{3}$

\begin{tabular}{|c|c|c|c|c|c||}
\hline Contact & $\mathrm{D}_{\mathrm{Zr}}$ & $\mathrm{D}_{\mathrm{Am}}$ & $\mathrm{D}_{\mathrm{Pu}}$ & $\mathrm{D}_{\mathrm{U}}$ & $\mathrm{D}_{\mathrm{Np}}$ \\
\hline $\mathrm{Sc} 1$ & 0.046 & 3.1 & 17.3 & 74.7 & 39.2 \\
\hline $\mathrm{Sc} 2$ & $<0.87$ & 3.3 & 4.5 & 61.8 & 21.1 \\
\hline $\mathrm{Sc} 3$ & $\mathrm{NA}$ & 3.3 & 6.5 & 60.1 & 21.1 \\
\hline
\end{tabular}

$\mathrm{NA}=$ No activity detected in either phase

The scrubbed solvent was stripped three times with 0.001 M HEDPA. Fresh HEDPA aliquots were used in each of the three contacts (St1-St3). The purpose of these contacts was to optimize the HEDPA strip concentration so that the phosphate 
(from the HEDPA) concentration in the HAW fraction would be at a minimum while still quantitatively stripping the actinides from the solvent. Strip distribution data using $0.001 \underline{\mathrm{M}}$ HEDPA are shown in Table 15.

Americium, uranium, and neptunium were quantitatively stripped from the solvent with $0.001 \mathrm{M}$ HEDPA. Not enough zirconium activity made it past the scrub contacts to determine it's distribution coefficient with $0.001 \mathrm{M}$ HEDPA. Plutonium stripping with $0.001 \underline{M}$ HEDPA may be a concern. $D_{\mathrm{Pu}_{\mathrm{u}}}$ is small for all three strip contacts, but because plutonium contributes to the majority of the activity, $D_{\mathrm{Pu}_{\mathrm{u}}}$ may have to be much smaller to prevent significant plutonium activities from either being washed out in the sodium carbonate or from being recycled with the solvent. $D_{\mathrm{Pu}}$ obtained from 0.5 M CMP stripped with 0.04 M HEDPA (Table 11) are an order of magnitude smaller than these obtained with $0.5 \underline{\mathrm{M}} \mathrm{CMP}$ and $0.001 \underline{\mathrm{M}}$ HEDPA. This data would indicate that an HEDPA concentration between $0.001 \underline{\mathrm{M}}$ and $0.04 \underline{\mathrm{M}}$ should efficiently strip plutonium.

Table 15: Strip Distribution Coefficients from 0.5 $\underline{\mathrm{M}} \mathrm{CMP}$ using $0.001 \underline{\mathrm{M}}$ HEDPA

\begin{tabular}{||c|c|c|c|c|c|c||}
\hline \hline Contact & $\mathrm{D}_{\mathrm{Zr}}$ & $\mathrm{D}_{\mathrm{Am}}$ & $\mathrm{D}_{\mathrm{Pu}_{\mathrm{u}}}$ & $\mathrm{D}_{\mathrm{U}}$ & $\mathrm{D}_{\mathrm{Np}}$ & $\mathrm{D}_{\mathrm{Tc}}$ \\
\hline $\mathrm{St} 1$ & $\mathrm{NA}$ & 0.56 & 0.18 & 1.98 & 0.04 & 21.3 \\
\hline $\mathrm{St} 2$ & $\mathrm{NA}$ & 0.05 & 0.14 & 0.1 & $<0.2$ & 40.2 \\
\hline St3 & $\mathrm{NA}$ & $\mathrm{NA}$ & 0.16 & 0.02 & $\mathrm{NA}$ & 61.6 \\
\hline
\end{tabular}

$\mathrm{NA}=$ No activity detected in either phase

Technetium was not stripped with the $0.001 \mathrm{M}$ HEDPA in $0.04 \mathrm{M} \mathrm{HNO}_{3}$, which was expected. Scrubbing technetium from the $0.5 \mathrm{M} \mathrm{CMP}$ with $0.05 \mathrm{M} \mathrm{H}_{2} \mathrm{C}_{2} \mathrm{O}_{4}$ in $3.0 \mathrm{M} \mathrm{HNO}_{3}$ was not evaluated but based on the scrub data shown in Table $6(0.75$ M CMP), significant technetium loss in the scrub section is not expected. In addition, sodium carbonate does not strip technetium from the $0.5 \mathrm{M}$ CMP. $0.25 \mathrm{M} \mathrm{Na}_{2} \mathrm{CO}_{3}$ contacts performed with the HEDPA stripped solvent, containing technetium, resulted 
in technetium D's between 1 and 3. These data suggest that $0.05 \underline{\mathrm{M} \mathrm{H}} \mathrm{H}_{2} \mathrm{C}_{4}$ in $3.0 \underline{\mathrm{M}}$ $\mathrm{HNO}_{3}, 0.001 \underline{\mathrm{M}} \mathrm{HEDPA}$ in $0.04 \underline{\mathrm{M}} \mathrm{HNO}_{3}$, and $0.25 \underline{\mathrm{M} \mathrm{Na}} \mathrm{CO}_{3}$ can not be used to strip technetium from the $0.5 \mathrm{M}$ CMP solvent. Ideally, it would be desirable to extract and recover technetium with the actinides. The apparent inability of $0.05 \mathrm{M}$ $\mathrm{H}_{2} \mathrm{C}_{2} \mathrm{O}_{4}$ in $3.0 \underline{\mathrm{M}} \mathrm{HNO}_{3}$, and $0.25 \underline{\mathrm{M} \mathrm{Na}} \mathrm{CO}_{3}$ to strip technetium is desirable but the lack of technetium stripping by $0.001 \underline{\mathrm{M}} \mathrm{HEDPA}$ in $0.04 \underline{\mathrm{M}} \mathrm{HNO}_{3}$ does cause some concern.

Technetium stripping tests were performed with $5 \underline{\mathrm{M}} \mathrm{HNO}_{3}$ using $0.5 \underline{\mathrm{M}} \mathrm{CMP}$ loaded with technetium from Run 74 calcine. Three sequential $5 \underline{\mathrm{M} \mathrm{HNO}} 3$ strip contacts were performed on unscrubbed solvent. An average $\mathrm{D}_{\mathrm{Tc}}=0.26$ was obtained from these strip contacts indicating that technetium can be recovered from the $0.5 \mathrm{M}$ CMP with $5 \underline{\mathrm{M}} \mathrm{HNO}_{3}$. 


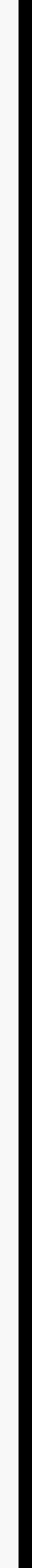




\section{RECOMMENDATIONS}

\section{Flowsheet Development Using the Generic TRUEX Model}

Experimental distribution coefficients were used in conjunction with the Generic TRUEX Model (GTM) to develop a flowsheet for the separation of the actinides from dissolved ICPP zirconium calcine using the CMP process. The experimental distribution coefficients for $\mathrm{Am}, \mathrm{Np}, \mathrm{Pu}, \mathrm{Tc}, \mathrm{U}$, and $\mathrm{Zr}$ were input into the GTM and the GTM was used to evaluate several specific flowsheets. As a result of this modelling, the flowsheet shown in Figure 4 is recommended for future flowsheet testing in the $5.5-\mathrm{cm}$ Centrifugal Contactor Mockup. The flowsheet consists of eight extraction stages at an $\mathrm{O} / \mathrm{A}=0.33$, four scrub stages at an $\mathrm{O} / \mathrm{A}=2.0$, four strip stages at an $\mathrm{O} / \mathrm{A}=1.0$, two sodium carbonate wash stages at an $\mathrm{O} / \mathrm{A}=5.0$, and one acid rinse stage at an $\mathrm{O} / \mathrm{A}=3.0$.

With this flowsheet, the total activity of the actinides is reduced from $1246 \mathrm{nCi} / \mathrm{g}$ in the feed to $0.19 \mathrm{nCi} / \mathrm{g}$ in the raffinate, which is below the NRC Class A LLW requirement. The 0.001 M HEDPA strip removed $99.8 \%$ of the Pu from the CMP solvent. The remaining $0.2 \%$ of the $\mathrm{Pu}$ was stripped in the sodium carbonate wash section, resulting in a Pu activity of $17.6 \mathrm{nCi} / \mathrm{g}$ in the wash effluent. The use of a higher concentration of HEDPA in the strip is expected to result in more complete stripping of $\mathrm{Pu}$, and a $\mathrm{Pu}$ concentration less than 10 $\mathrm{nCi} / \mathrm{g}$ in the sodium carbonate effluent.

Zirconium was effectively scrubbed from the CMP solvent, resulting in less than $0.01 \%$ of the $\mathrm{Zr}$ exiting in the strip product. The $\mathrm{Tc}$ which was extracted from the dissolved calcine feed was not stripped, resulting in Tc building up to $0.023 \mathrm{Ci} / \mathrm{m}^{3}$ in the solvent and $96 \%$ of the Tc exiting in the aqueous raffinate. 




\begin{tabular}{|c|c|c|c|c|c|c|c|c|c|c|}
\hline Comp. & $\begin{array}{c}\text { Dissolved } \\
\text { Calcine } \\
\text { Feed } \\
1\end{array}$ & $\begin{array}{c}\text { CMP Solvent } \\
\text { Feed } \\
2 \\
\end{array}$ & $\begin{array}{c}\text { LAW } \\
\text { Raff. } \\
3\end{array}$ & $\begin{array}{c}\text { Scrub } \\
\text { Feed } \\
4 \\
4\end{array}$ & $\begin{array}{c}\text { Strip } \\
\text { Feed } \\
5 \\
\end{array}$ & $\begin{array}{c}\text { Strip Product } \\
6 \\
\end{array}$ & $\begin{array}{c}\text { Wash } \\
\text { Feed } \\
7 \\
\end{array}$ & $\begin{array}{c}\begin{array}{c}\text { Wash } \\
\text { Effluent }\end{array} \\
8 \\
\end{array}$ & $\begin{array}{c}\text { Rinse } \\
\text { Feed } \\
9\end{array}$ & $\begin{array}{c}\begin{array}{c}\text { Rinse } \\
\text { Effluent }\end{array} \\
10\end{array}$ \\
\hline $\mathrm{HNO}_{3}(\mathrm{M})$ & 3.5 & & 2.9 & 3.0 & & & & & 0.10 & 0.10 \\
\hline HEDPA (M) & & & & & 0.001 & 0.001 & & & & \\
\hline $\mathrm{H}_{2} \mathrm{C}_{2} \mathrm{O}_{4}(\mathrm{M})$ & & & & 0.05 & & & & & & \\
\hline $\mathrm{Na}_{2} \mathrm{CO}_{3}(\mathrm{M})$ & & & & & & & 0.25 & 0.25 & & \\
\hline $\mathrm{Zr}(\underline{\mathrm{M}})$ & 0.21 & & 0.17 & & & $1.86 \mathrm{E}-05^{1}$ & & & & \\
\hline $\mathrm{Am}(\mathrm{nCi} / \mathrm{g})$ & 104 & & 0.17 & & & 309 & & & & \\
\hline $\mathrm{Pu}(\mathrm{nCi} / \mathrm{g})$ & 1142 & & 0.02 & & & 3275 & & 17.6 & & \\
\hline $\mathrm{U}(\mathrm{nCi} / \mathrm{g})$ & 0.05 & & $1.58 \mathrm{E}-07$ & & & 1.5 & & 0.011 & & \\
\hline $\mathrm{Np}(\mathrm{nCi} / \mathrm{g})$ & 0.5 & & $1.52 \mathrm{E}-06$ & & & 1.5 & & & & \\
\hline $\mathrm{Tc}\left(\mathrm{Ci} / \mathrm{m}^{3}\right)$ & 0.06 & 0.023 & 0.048 & & & 0.0013 & & 0.021 & & \\
\hline $\begin{array}{c}\text { Relative } \\
\text { Flow } \\
\end{array}$ & 1.00 & 0.40 & 1.20 & 0.21 & 0.40 & 0.40 & 0.08 & 0.08 & 0.13 & 0.13 \\
\hline
\end{tabular}

Figure 4. CMP Flowsheet for the Treatment of ICPP Dissolved Zirconium Calcine 


\section{CONCLUSIONS}

Conclusions drawn from tests conducted with the CMP extractant and dissolved Run 74 zirconium calcine are:

- A solvent composition of $0.5 \underline{\mathrm{M}} \mathrm{CMP}$ and $1.0 \underline{\mathrm{M}} \mathrm{TBP}$ in an Isopar $\mathrm{L}^{\circledR}$ diluent is recommended for use with the current contactor design. This solvent composition was tested in the $5.5 \mathrm{~cm}$ Centrifugal Contactor Mockup and provided good hydraulic properties and is expected to provide actinide decontamination below the $10 \mathrm{nCi} / \mathrm{g}$ NRC limit [26]. Extraction distribution coefficients for the actinides using this solvent are expected to be: $\mathrm{D}_{\mathrm{Am}} \sim 7, \mathrm{D}_{\mathrm{Np}} \sim$ $60, D_{\mathrm{Pu}} \sim 80$ and $\mathrm{D}_{\mathrm{U}} \sim 200$. Zirconium extraction is minimal, $\mathrm{D}_{\mathrm{Zr}}<0.3$, but is significant enough to make it desirable to prevent it from reporting to the HAW fraction. Comparable extraction D's for $\mathrm{Nd}$ (Am surrogate) and $\mathrm{Zr}$ were obtained in the $5.5 \mathrm{~cm}$ Centrifugal Contactor Mockup [26]. $\mathrm{D}_{\mathrm{rc}}$ is also small $(\sim 0.7)$ indicating complete extraction of technetium from the dissolved calcine feed may be difficult.


$3.0 \mathrm{M} \mathrm{HNO}_{3}$ should be used to selectively scrub extracted zirconium from the solvent. The high acid concentration of the scrub will inhibit actinide recycle.


$\mathrm{HNO}_{3}$ scrub solution and the distributions were similar to those reported in this study [26]. Less than $0.1 \%$ of the $\mathrm{Zr}$ in the feed reported to the HAW fraction in the $5.5 \mathrm{~cm}$ Centrifugal Contactor Mockup [26]. Tc-99 is not expected to be signifigantly scrubbed from the solvent with $0.05 \mathrm{M} \mathrm{H}_{2} \mathrm{C}_{2} \mathrm{O}_{4}$ in $3.0 \mathrm{M} \mathrm{HNO}_{3}$.

- A strip solution concentration between $0.001 \mathrm{M}$ and $0.04 \mathrm{M}$ HEDPA in 0.04 
$\underline{\mathrm{M}} \mathrm{HNO}_{3}$ will remove the actinides from the $0.5 \mathrm{M} \mathrm{CMP}$ solvent. Even though $\mathrm{D}_{\text {Act }}$ were small using $0.001 \underline{\mathrm{M}}$ HEDPA, the $\mathrm{D}_{\mathrm{Pu}_{\mathrm{u}}} \sim 0.2$ may be too large for complete plutonium stripping. This may result in greater than Class $\mathrm{A}$ plutonium activities in the sodium carbonate wash or may cause significant plutonium activities in the recycled solvent. $0.04 \mathrm{M}$ HEDPA efficiently stripped the actinides from $0.5 \mathrm{M}$ CMP; this was confirmed in the $5.5 \mathrm{~cm}$ Centrifugal Contactor Mockup [26]. The phosphate from $0.04 \underline{\mathrm{M}}$ HEDPA may increase the final HAW glass or glass-ceramic waste volume. Minimizing the phosphate concentration (or HEDPA concentration) will have a direct correlation in minimizing the final waste volume.

- Technetium is not stripped from the $0.5 \mathrm{M}$ CMP with either $0.001 \mathrm{M}$ HEDPA in $0.04 \underline{\mathrm{M}} \mathrm{HNO}_{3}$ or $0.25 \underline{\mathrm{M} \mathrm{Na}} \mathrm{CO}_{3}$. $5 \mathrm{M} \mathrm{HNO}_{3}$ will efficiently strip technetium; thus allowing for technetium disposal with the actinides in the HAW fraction.

- Reducing the zirconium calcine feed with an extremely small volume of $30 \%$ $\mathrm{H}_{2} \mathrm{O}_{2}$ will prevent the extraction of dichromate into the CMP solvent. Hydrogen peroxide reduces the extractable dichromate to the less extractable $\mathrm{Cr}(\mathrm{III})$. CMP solvent contacted with reduced feed remains opaque, as opposed to dark yellow/green. Inhibiting dichromate extraction will also decrease the likelihood of precipitation, interfacial crud, and third phase formation. These problems were observed (sporadically) when performing tests with unreduced feeds. In the $5.5 \mathrm{~cm}$ Centrifugal Contactor Mockup test, $<0.2 \%$ of the chromium reported to the HAW fraction [26].

- The flowsheet shown in Figure 4 is expected to reduce the concentration of the actinides to below the $10 \mathrm{nCi} / \mathrm{g}$ Class A LLW requirements and minimize the quantity of zirconium reporting the the HAW strip product. 


\section{REFERENCES}

1. J. A. Murphy, L. F. Pincock, and I. N. Christiansen, "ICPP Radioactive Liquid and Calcine Waste Technologies Evaluation Final Report and Recommendations", Lockheed Idaho Technologies Co., INEL-94/0119, April 1995.

2. J. R. Berreth, "Inventories And Properties Of ICPP Calcined High-Level Waste", Westinghouse Idaho Nuclear Co. Inc., WINCO-1050, February 1988.

3. B. A. Staples, G. S. Pomiak, and E. L. Wade, "Properties of Radioactive Calcine Retrieved From The Second Calcine Solids Storage Facility At ICPP", ICP-1189, March 1979.

4. K. N. Brewer, et al., "Dissolution Of Two NWCF Calcines: Extent Of Dissolution And Characterization of Undissolved Solids", Lockheed Idaho Technologies Co., INEL95/0098, February 1995.

5. R. S. Herbst, et al., "Experimental Results: Pilot Plant Calcine Dissolution And Liquid Feed Stability", Lockheed Idaho Technologies Co., INEL-95/0097, February 1995.

6. P. C. Butler, and D. R. Trammell, "Technical Division Quarterly Progress Report, October 1 - December 31, Calcine Dissolution Experiments", Allied Chemical, February 1978.

7. B. E. Paige, "Leachability Of Aluminum Calcine Produced In The Idaho Waste Calcination Facility", IN-1011, July 1966.

8. L. D. McIsaac, J. D. Baker, J. W. Tkachyk, "Actinide Removal From ICPP Waste", Allied Chemical Corporation, ICP-1080, Aug. 1975.

9. W.W. Schulz, ARH, SA-203, 1974.

10. J. D. Baker, L. D. McIsaac, J. F. Krupa, D. H. Meikrantz, and N. C. Schroeder, "Experimental Mixer Settler Actinide Partitioning From ICPP Acidic Waste", Allied Chemical Idaho Chemical Programs, ICP-1182, Aug. 1979.

11. Experimental data; unpublished

12. B. J. Mincher, "Application Of TRUEX To Actual ICPP High-Level Waste", $15^{\text {th }}$ Actinide Separations Conference, Charleston, SC, June 17-21, 1991.

13. J. D. Law, et. al., "CMP Flowsheet Development for the Separation of Actinides from ICPP Sodium-Bearing Waste using Centrifugal Contactors", Lockheed Idaho 
Technologies Co., INEL-95/0414, August 1995.

14. B. M. Rapko and G. J. Lumetta, "Extraction of Transuranic Elements with a DihexylN,N-diethylcarbamoylmethyl Phosphonate/Tributyl Phosphate System - Initial Investigations", Solvent Extraction and Ion Exchange, 12(5), 967-986, 1994.

15. H. R. Maxey, et. al., "Removal of Actinides from ICPP Fuel Reprocessing Wastes Engineering Studies Terminal Report", Exxon Nuclear Idaho Co., ENICO-1057, September 1980.

16. J. F. Krupa, et. al., "Actinide Partitioning from ICPP Waste: An Investigation of Methods to Eliminate Mercury Interference", Allied Chemical, ICP-1181, March 1979.

17. J. J. Katz, G. T. Seaborg, and L. R. Morss, The Chemistry of the Actinide Elements, $2^{\text {nd }}$ Edition, Vol. 1, Chapman and Hall, New York, NY, 1986.

18. A. C. Muscatello, et. al., "Comparison Between CMPO and DHDECMP for Alpha Decontamination of Radioactive Liquid Waste", Los Alamos National Laboratory, LAUR-90-1592.

19. J. D. Law, R. S. Herbst, and A. M. Rodriguez, "CMP Flowsheet Development for the Separation of Actinides from ICPP Sodium-Bearing Waste Using Centrifugal Contactors", Lockheed Idaho Technologies Co., INEL-95/0414, August 1995.

20. R. S. Herbst, A. M. Rodriguez, K. N. Brewer, T. G. Garn, and R. T. Tillotson, "Extraction of Actinides from Idaho Chemical Processing Plant Sodium-Bearing

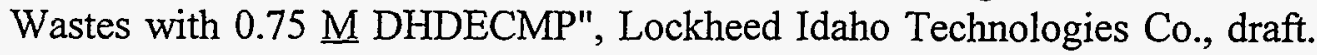

21. L. D. McIsaac, J. D. Baker, J. F. Krupa, D. H. Meikrantz, and N. C. Schoeder, "Flowsheet Development Work at the Idaho Chemical Processing Plant for the Partitioning of Actinides from Acidic Nuclear Waste", Actinide Separations Symposium Pacific Chemical Conference, Honolulu, Hawaii, April 1-6, 1979.

22. W. W. Schulz, and L. D. McIsaac, "Bidentate Organophosphorus Extractants: Purification, Properties, and Application to Removal of Actinides from Acidic Waste Solutions", Atlantic Richfield Hanford Co., ARH-SA-263, May 1977.

23. W.W. Schulz, L. L. Burger, and J. D. Navratil, Science and Technology of Tributyl Phosphate, Volume III, CRC Press, Inc., Boca Raton, Florida, 1990.

24. W. W. Schulz, and L. D. McIsaac, "Removal of Actinides from Nuclear Fuel Reprocessing Waste Solutions with Bidentate Organophosphorus Extractants", Atlantic Richfield Hanford Co., ARH-SA-217, August 1975. 
25. D. S. Wisnubroto, et. al., "Solvent Extraction of Neptunium by n-octyl(phenyl)-N,Ndiisobutylcarbamoylmethylphosphine Oxide from Nitric Acid Solution Containing Hydrogen Peroxide", Solvent Extraction and Ion Exchange, 11(4), 569-583, 1993.

26. J. D. Law, R. S. Herbst, and K. N. Brewer, "CMP Flowsheet Development for the Separation of Actinides from Dissolved ICPP Calcine Using Centrifugal Contactors", Lockheed Idaho Technologies Co., INEL-95/0582, November 1995. 


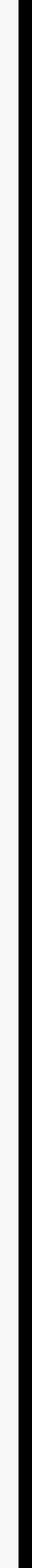

